\title{
Homocysteine promotes migration of adventitial fibroblasts via Angiotensin II type 1 receptor activation to aggravate atherosclerosis
}

\section{Zhibo Zhu}

Inner Mongolia Medical University

\section{Xiangyu Hao}

Inner Mongolia Medical University

Tianxiang Li

Inner Mongolia Medical University

Jianqiang Guo ( $\sim$ guojianqiang@immu.edu.cn )

Inner Mongolia Medical University https://orcid.org/0000-0002-5159-0739

\section{Research article}

Keywords: homocysteine, angiotensin II type 1 receptor, adventitial fibroblasts, migration, invasion, atherosclerosis

Posted Date: October 5th, 2020

DOI: https://doi.org/10.21203/rs.3.rs-32632/v2

License: (9) (1) This work is licensed under a Creative Commons Attribution 4.0 International License. Read Full License 


\section{Abstract}

Background: Hyperhomocysteinemia (HHcy) is an independent risk factor for atherosclerosis. However, the mechanisms of HHcy-induced arteriosclerosis are largely unknown.

Objective: To clarify the effect of Hcy on adventitial fibroblasts (AFs) and its relation with angiotensin II type 1 receptor (AT1R).

Method: The apolipoprotein E gene-deficient mice (Apoe-/-) were used as the murine model for atherosclerosis. HHcy was induced and treated by feeding them $1.5 \%$ methionine and telmisartan (gavage $10 \mathrm{mg} / \mathrm{kg} / \mathrm{d}$ ) for 12 weeks, respectively. The AFs and HEK293A cells transfected with the AT1R plasmid were used to investigate the interaction between Hcy and AT1R. All data were expressed as mean \pm SEM. The data were analyzed by one-way ANOVA or repeated measurement ANOVA.

Results: HHcy aggravated the plaque area of the aortic root and increased the expression of IL-6, MCP-1, and the macrophage marker Mac3 in the plaque and adventitia of the aorta, whereas telmisartan improved this effect. Hyperhomocysteinemia induced the occurrence of the AFs marker protein ER-TR7 in the plaque and the entire layer of the aorta, whereas telmisartan also improved this effect, indicating that hyperhomocysteinemia induced AFs migration and that AT1R mediated this process. Hcy increased the production of AFs $\mathrm{H} 2 \mathrm{O} 2$, ROS, and IL-6 of AFs, indicating that Hcy activated the oxidative stress and inflammatory reactions, which may induce cell migration. The subsequent scratch and transwell experiments confirmed that Hcy induced the AFs migration and that telmisartan inhibited this effect. Hcy increased the expression of AFs AT1R and the phosphorylation levels of PKC and ERK1/2 in the AF and HEK293A cells transfected with the AT1R plasmid, whereas telmisartan inhibited this effect, indicating that Hcy activated AT1R intracellular signaling pathway.

Conclusion: Hcy promoted adventitial inflammation, induced AFs migration, and aggravated atherosclerosis by activating AT1R.

\section{Background}

Hcy is a nonessential sulfur-containing amino acid derived from the essential amino acid methionine and actively participates in various biochemical reactions. ${ }^{1}$ HHcy (circulating Hcy $\geq 15 \mu \mathrm{m}$ ) is an independent risk factor for many cardiovascular diseases, such as atherosclerosis, coronary heart disease, and abdominal aortic aneurysm. Although there is evidence that HHcy can cause vasodilation, damage endothelial cells, promote intravascular proliferation, promote outer membrane activation, and disrupt hemostasis/coagulation, ${ }^{2-5}$ the mechanism by which Hcy aggravates atherosclerosis remains elusive.

AT1R is a key player in the renin-angiotensin system. AT1R activation leads to cardiac remodeling, ventricular hypertrophy, intimal formation, smooth muscle cell proliferation, and migration. ${ }^{6,7}$ Genetic deletion of AT1R effectively prevents pathological vascular injuries in various animal models, such as 
models hypertension and atherosclerosis. ${ }^{8}$ Although recent studies indicate Hcy directly interacts and activates AT1R to aggravate vascular injury ${ }^{1}$ and Hcy accelerates collagen accumulation in the adventitia of balloon-injured rat carotid arteries via AT1R expression, ${ }^{9}$ little is known about the association between Hcy and AT1R in atherosclerosis.

Migration and proliferation responses of cells in the vascular wall and deposition of extracellular matrix (ECM) play a key role in restenosis and atherosclerosis. ${ }^{10}$ Although medial smooth muscle cells have been regarded as the main source of cells, ${ }^{11,12}$ there is now increasing evidence that the adventitial layer can also be a significant contributor to the arterial remodelling process through increased angiogenesis. ${ }^{13}$ Findings by Richard C.M. et al. ${ }^{10}$ provide direct evidence that adventitial fibroblasts migration contribute to neointima formation after balloon injury. Hcy induced AT1R expression that activates various signaling molecules extracellular signal-regulated protein kinases 1 and 2 (ERK-1/2) and protein kinase $C$ (PKC). These signaling molecules activation can promote cell migration and invasion. ${ }^{14-16}$ However, the precise role of Hcy in the migration and invasion of adventitia fibroblasts is unclear in the process of atherosclerosis formation.

Therefore, we investigated whether HHcy stimulates AFs migration and invasion in mice via AT1R activation to accelerate the formation atherosclerosis.

\section{Methods}

\section{Materials}

L-homocysteine (69453), telmisartan (T8949), was purchased from Sigma-Aldrich. Disposable consumables such as cell culture bottle and 6-well plates were purchased from Guangzhou Jet BioFiltration Co., Ltd.

\section{Animals and Treatments}

A total of 21 ApoE-/- mice (male, 8 weeks) were purchased from Beijing Vital River Laboratory Animal Technology Co., Beijing, China (Ltd. Number: SCXK2016-0006). The mice were randomly divided into three groups: a control group with a standard mouse diet $(n=7)$, an HHcy group fed with standard mouse diet plus $1.5 \%$ methionine $(n=7),{ }^{17,18}$ and a telmisartan gavage group (HHcy+Telmi) treated with telmisartan $(10 \mathrm{mg} / \mathrm{kg} /$ day). Ten Sprague Dawley (SD) rats (male, weighing 150-200 grams) were purchased from Inner Mongolia Medical University Laboratory (Hohhot, China). All animal experiments were approved by the Institutional Animal Care and Use Committee (No: YKD2015110) of Inner Mongolia Medical University, Hohhot, China and was conducted in accordance with the Guide for the Care and Use of laboratory animals from the National Institutes of Health(Bethesda, MD, USA).

\section{Tail-cuff measurement of systolic blood pressure}


Systolic blood pressure (SBP) was recorded by a computerized non-invasive tail-cuff system (Cat. NO.BP300A, Chengdu Techman Software CO.,LTD). Measurements were performed in quiet environment to avoid causing mice anxiety. The mice underwent 7 consecutive days of training sessions to become accustomed to the tail-cuff procedure. Blood pressure of mice underwent 12 consecutive weeks was measured from 1 to 6 PM on weekends every week. Three measurements were weekly performed on each mouse, so that the average of total of 3 measurements was represented as the SBP of each mouse.

\section{Measurement of Serum Homocysteine Level}

The levels of TG, TC, HDL, and LDL were assessed with kits from Beijing Sino-UK Institute of Biological Technology. Hcy concentration was measured using enzyme-linked immunosorbent assay (HY-N0080) in Beijing Sino-UK Institute of Biological Technology.

\section{Histology and Immunostaining}

The heart and approximately $2 \mathrm{~mm}$ of proximal aortas were fresh frozen in OCT compound. ${ }^{20}$ Tissue samples were cut into $7 \mu \mathrm{m}$ thin slices. Frozen tissue sections were stained with Oil Red O, H\&E, Masson, and immunostaining. ${ }^{21} \mathrm{~A}$ Masson's trichrome staining kit was used to detect collagen deposition in the atherosclerotic plaque. Analyzed with Image-Pro Plus 6.0 or ImageJ software. ${ }^{20}$

Cryosections were fixed in $4 \%$ paraformaldehyde and subsequently treated with $\mathrm{H}_{2} \mathrm{O}_{2}$ and after the primary antibody was blocked in $5 \%$ goat serum $(1: 100)$ at $4^{\circ} \mathrm{C}$ overnight. The tissue sections were washed in PBS then incubated with secondary antibody (1:100). They were incubated in diaminobenzidine until a change in color was observed under the microscope and then the nucleus was stained with hematoxylin. ${ }^{22}$ Immunofluorescence staining procedure was similar to immunostaining.

\section{Cell Culture}

\section{Primary Rat AFs}

Cells were prepared according to common methods ${ }^{19}$ and with some modifications. SD rat were euthanized with sodium pentobarbital at $120 \mathrm{mg} / \mathrm{kg}$. Thoracic aortas were removed and cleaned under sterile conditions. The adventitia was stripped from the aorta and cut into pieces about 2-3 mm3 in size. Then, the tissue pieces were attached to the 6-well plates and immersed in Dulbecco's modified Eagle's medium (DMEM, Gibco) containing 30\% fetal bovine serum (FBS, Gibco) and maintained at $37^{\circ} \mathrm{C}, 5 \%$ $\mathrm{CO}_{2}$. Cells were collected, and when the cells grew to about $70 \%-80 \%$ fusion, the tissue pieces could be cultured again. AFs were verified by positive immunofluorescent staining of vimentin and ER-TR7. The AFs after passage were cultured in DMEM supplemented with $10 \% \mathrm{FBS}$ at $37^{\circ} \mathrm{C}, 5 \% \mathrm{CO}$. All $\mathrm{AFs}$ used in this study were from early passage with a maximum of four passages.

The human embryonic kidney cell line HEK293A was a generous gift from our laboratory and cultured in DMEM (high glucose) supplemented with $10 \% \mathrm{FBS}$ at $37^{\circ} \mathrm{C}$ in a humidified atmosphere containing $5 \%$ 
$\mathrm{CO}_{2}$. The cells were confirmed of no mycoplasma contamination before application.

\section{Cell Proliferation Assay}

The proliferation of cells was examined with Cell Counting Kit-8 (Cat. NO. K1018, ApexBio Technology LLC). Briefly, cells were seeded in 96-well plates with $5 \times 10^{3}$ cells/well, cultured for 24 hours, and subjected to the indicated treatment. ${ }^{23}$ The absorbance at $450 \mathrm{~nm}$ was measured using an automatic microplate reader $(n=3)$.

\section{Wound-Healing Assay}

AFs $\left(5 \times 10^{5}\right.$ cells/well) were inoculated into 12-well plates. After the cells completely covered the bottom wall of the 12-well plate, three vertical lines were drawn in the 12-well plate with a sterile 200- $\mu$ l pipette tip, and the floating cells were removed by PBS washing. ${ }^{24}$ DMEM $1000 \mu$ l containing $1 \%$ FBS and Hcy 200 $\mu \mathrm{mol} / \mathrm{L}$ was added into the 6 -well plate. The cells were cultured in an incubator at $37^{\circ} \mathrm{C}$ and $5 \% \mathrm{CO}_{2}$ for 48 hours. At the same location, the images of 0 and 48 hours were taken to observe the cell migration. Cell migration analysis was processed by Image-Pro Plus 6.0 software $^{24}(n=3)$.

\section{Transwell Matrigel Invasion Assays}

Transwell Matrigel invasion assays were performed using a transwell membrane (8- $\mu \mathrm{m}$ pore size, $6.5-\mathrm{mm}$ diameter; Cat. NO. 35488, Corning Incorporated) in a 24-well plate. The Hcy-treated cells were digested with trypsin $(0.25 \%)$ and then centrifuged and the supernatant was discarded. The cell suspension was prepared with DMEM without serum. The cells $\left(1 \times 10^{5}\right.$ cells/well) were loaded to the upper side of the chamber $(500 \mu \mathrm{l} /$ well), and the lower chambers contained $750 \mu \mathrm{l} /$ of DMEM with $10 \%$ FBS as chemoattractant. The cells were cultured in the cell incubator for 6 hours. The filter inserts were then removed from the wells. Cells on the upper surface of the filter were removed using cotton swabs and the membranes were fixed and stained with crystal violet reagent. ${ }^{21,25}$ Invasion was quantified by counting 5 random fields under a light microscope (Leica, Germany) at x40 magnification.

\section{Detection of Intracellular ROS}

Intracellular ROS generation was monitored by using Reactive Oxygen Species Assay Kit (WLA070a, Wanleibio). Cells $\left(1 \times 10^{6}\right.$ cells/well) were seeded in 6-well plates. Cells were treated with Hcy for 48 hours and stained with $20 \mu \mathrm{mol} / \mathrm{L}$ DCF-DA in culture medium for 30 minutes in the dark. The cells were then harvested and washed in PBS three times and oxidation-induced DCF fluorescence was assayed by fluorescence microscopy. ${ }^{26}$

\section{Assay of Hydrogen Peroxide Level}

Hydrogen peroxide level was assayed using a Hydrogen Peroxide Assay Kit (Cat. NO. A064-1-1, Nanjing Jiancheng Bioengineering Institute, China) according to the manufacturer's instructions. 


\section{Western Blot Analysis}

Protein extracts $(40 \mu \mathrm{g})$ were resolved by $10 \%$ SDS-PAGE for western blot analysis. The blots were subsequently incubated with primary antibodies (AT1R, 1:300, Abcam, ab124734; p-PKC, 1:1000, Cell Signaling Technology, 9371s; t-PKC, 1:1000, Wanleibio, WL02234; p-ERK1/2, 1:1000, Cell Signaling Technology, 9101s; t-ERK1/2, 1:1000, Cell Signaling Technology, 9102s). The corresponding secondary antibody was added for incubation at room temperature. The protein expressions in different samples were detected using the enhanced chemiluminescence method.

\section{Statistical Analysis}

All data were expressed as mean \pm standard error of the mean (SEM), except Table 1 and table 2 (mean \pm standard deviation). All experiments were repeated at least three times. The data were analyzed by GraphPad Prism 5.0 (GraphPad Software, San Diego, California, USA) and SPSS version 19.0 (SPSS Inc., Chicago, IL, USA). The data were analyzed by one-way ANOVA or repeated measurement ANOVA, without assuming sphericity. When multiple measurements were made in the same cell, Greenhouse-Geisser correction was performed. The data that failed to pass the normality test were analyzed by nonparametric test. The difference was significant $(P<0.05)$.

\section{Results}

\section{Vital parameters}

HHcy was induced by feeding ApoE-/- mice a high-methionine diet for 12 weeks. The results showed that serum Hcy concentrations in the HHcy group were significantly higher $(35.89 \pm 3.26 \mu \mathrm{mol} / \mathrm{L})$ than the control group $(23.85 \pm 2.09 \mu \mathrm{mol} / \mathrm{L}),\left({ }^{*} \mathrm{P}<0.05\right)$. Therefore, the high-methionine diet significantly increased serum concentrations of Hcy, suggesting that the diet-induced HHcy model was successful (Table 1). Total cholesterol (TC), and high-density lipoprotein (HDL) in HHcy group were significantly difference except triglyceride (TG). TC level in HHcy group was higher than that in control group $(\mathrm{P}<$ 0.05). TC decreased significantly after telmisartan treatment $(P<0.05)$, Low-density lipoprotein $(L D L)$ level in HHcy group was higher than that in control group, but there was no statistical significance. After telmisartan treatment, LDL decreased significantly $(P<0.05)$, as shown in Table 1.

Telmisartan treatment decreased systolic blood pressure; however, there was no statistical difference in three groups, showing no significant changes in body weight (Table 2).

\section{HHcy accelerates atherosclerosis formation}

A large amount of lipid deposition was found in the aortic root of mice in the HHcy group. The area of atherosclerotic plaque accounted for about (23.1\%) of the aortic root, which was larger than that in the control group (6.3\%), as shown by the Oil Red $\mathrm{O}$ staining. The plaque area in the HHcy+Telmi group (9.1\%) was significantly lower than in the HHcy group (Fig. 1). These results demonstrated that Hcy significantly induced atherosclerosis in ApoE-/- male mice, which may be related to AT1R activation. 


\section{The AT1R mediates HHcy-aggravated plaque instability}

Hematoxylin and eosin staining showed higher number of foam cells and a larger acellular necrotic core area in the HHcy group, which was improved in the HHcy+Telmi group (Fig. 2a). Moreover, Masson staining (Figs. 2b and 2c) showed that total collagen content, expressed as a percentage of the section area, was significantly reduced in HHcy group compared with that in control group $(P<0.001)$, while it was significantly increased in the HHcy+Telmi group. These results suggested that Hcy increased plaque instability via AT1R.

\section{HHcy exaggerated atherosclerotic plaque inflammation in $\mathrm{ApoE}^{-1-}$ male mice.}

The number of inflammatory cells such as MCP-1, IL-6, and Mac3 in aortic root plaques in HHcy group was significantly higher than that in control group $(P<0.05)$, while it was reduced in the HHcy+Telmi group (Figs. $3 \mathrm{a}$ and $\mathrm{3b}$ ). These results suggested that HHcy increased the infiltration of inflammatory cells in plaques and accelerated the progression of atherosclerosis via AT1R.

\section{HHcy amplifies aortic adventitial inflammation in $\mathrm{ApoE}^{\prime-}$ male mice}

Results showed that inflammatory cells MCP-1, IL-6, and Mac3 were preferentially produced in the adventitial layer. Quantitative analysis of aortic adventitia revealed higher expression of MCP1, IL-6, and Mac3 in the HHcy group than in control group. Furthermore, the AT1R blocker telmisartan markedly attenuated MCP1, IL-6, and Mac3 expression (Fig. 4), which is consistent with observations in a previous study. ${ }^{2}$ These results demonstrated that Hcy significantly exaggerated vascular inflammation in $\mathrm{ApoE}^{-/-}$ male mice, which may be related to AT1R activation.

\section{HHcy induces AFs migration in ApoE'- male mice}

Immunofluorescence was used to detect AFs marker ER-TR7 (Fig. 5). In the control group, staining showed ER-TR7 expression in aortic adventitia. Moreover, deposition of ER-TR7 increased in the whole aortic wall and plaque in the HHcy group. This phenomenon was reduced by telmisartan, as shown in the HHcy+Telmi group. These results further demonstrated that Hcy induced AFs migration and invasion in ApoE-/- male mice, which may be related to AT1R activation.

\section{Hcy upregulates proinflammatory effects in AFs of rat}

Our results showed that $\mathrm{Hcy}$ of $200 \mu \mathrm{mol} / \mathrm{L}$ greatly enhanced hydrogen peroxide $\left(\mathrm{H}_{2} \mathrm{O}_{2}\right)$ secretion (Fig. 6a) and increased intracellular ROS at 48 hours after stimulation (Fig. 6b). Hcy induced IL-6 expression in a time-dependent manner, and the most effective Hcy time was 36 hours as indicated by using western blot (Figs. 6c and 6d). These results demonstrated that Hcy could activate AFs oxidative stress and inflammatory response.

\section{Hcy induces expression of MMP-9 in AFs}


Hcy induced MMP-9 expression in a time-dependent manner, and the most effective Hcy time was 36 hours as indicated by using western blot (Fig. 7). Matrix remodeling is a critical step to initiate and support AFs motility.

\section{HHcy induces AFs proliferation, migration, and invasion}

AFs were treated with increasing concentrations of $\operatorname{Hcy}(0,50,100,200$, and $400 \mu \mathrm{mol} / \mathrm{L})$ for 48 hours. Results showed that cell viability was increased significantly in a dose-dependent manner, indicating that Hcy promoted cell proliferation (Fig. 8a). Cells were treated with $200 \mu \mathrm{mol} / \mathrm{L} \mathrm{Hcy} \mathrm{for} 48$ hours. The wound areas of the cells were observed via scratch assay under a microscope at 0 hour and 48 hours. Results showed that Hcy significantly increased cell migration (Figs. 8b and 8c). Cell invasion was detected by transwell Matrigel invasion assays. In AFs stimulated by $200 \mu \mathrm{mol} / \mathrm{L}$ Hcy for 48 hours, cell invasion was significantly increased (Figs. $8 \mathrm{~d}$ and $8 \mathrm{e}$ ). After telmisartan $(1 \mathrm{mmol} / \mathrm{L})$ pretreatment for 1 hour, this phenomenon was inhibited. Our results suggested that Hcy promoted migration and invasion via AT1R activation in AFs.

\section{Hcy enhances AT1R expression in cultured AFs}

Hcy induced AT1R expression in a time-dependent manner as indicated by using western blot (Fig. 9). There was a significant increase in AT1R expression at 36 hours (Figs. 9a and 9c). Moreover, Hcy of 50 to $300 \mu \mathrm{mol} / \mathrm{L}$ significantly facilitated AT1R expression, with a peak at $200 \mu \mathrm{mol} / \mathrm{L}$ (Figs. 9b and 9d). This phenomenon was further verified by immunofluorescence staining of AT1R protein (Fig. 9e).

\section{Hcy activates AT1R signaling}

We assessed G protein-dependent signaling PKC and ERK1/2 phosphorylation in AFs. The phosphorylation of ERK1/2 and PKC was increased after stimulated with Hcy $(200 \mu \mathrm{mol} / \mathrm{L})$, which was decreased by telmisartan pretreatment (1 mmol/L) (Figs. 10a to 10c).

To further verify the results, we constructed EGFP-AT1R fusion protein particles and transfected HEK293A cells to assess the effect of Hcy on PKC and ERK1/2 signaling pathways. We used agarose gel electrophoresis to detect the extracted plasmids and transfected into HEK293A cells (Figs. 11a and 11b). Western blot indicated AT1R levels in HEK293A cells (Figs. 11 c and 11d). The results confirmed the successful construction of the plasmids by GeneChem Co. Ltd. (Shanghai, China) (Fig. 11a).

Fluorescence microscopy showed that the green fluorescence was much brighter in the HEK293A cells transfected with AT1R compared with the control group (Fig. 11b). Western blot indicated higher AT1R expression in plasmids transfected into HEK293A cells than in the control group (Figs. 11c and 11d).

These results indicated that the plasmid was successfully constructed and transfected into HEK293A cells.

In HEK293A cells transfected with AT1R, Hcy at $200 \mu \mathrm{mol} / \mathrm{L}$ resulted in delayed but sustained PKC and ERK1/2 phosphorylation, which was decreased by telmisartan pretreatment ( $1 \mathrm{mmol} / \mathrm{L})$ (Figs. 12a to 
12c). These results suggested that Hcy could activate the downstream PKC and ERK1/2 signaling pathway downstream of AT1R.

\section{Discussion}

Previous studies have demonstrated that AFs migrate from the adventitia to the neointima upon balloon injury in rats. ${ }^{10}$ Recent data have demonstrated that Hcy directly interacted and activated with AT1R to aggravate adventitial inflammation, collagen accumulation, and vascular injury. ${ }^{1,2,9}$ However, little is known about the possible mechanisms by which Hcy can promote AFs migration and invasion and accelerate atherosclerosis formation via AT1R activation. This study revealed that Hcy induced AFs migration and invasion, which was inhibited with telmisartan treatment, an AT1R inhibitor. Furthermore, Hcy increased the expression of AT1R and MMP9 in AFs and activated the ERK and PKC signaling pathway of AT1R.

A large body of evidence suggests the crucial role that dyslipidemia play in vascular pathology associated with HHcy. ${ }^{27}$ Vascular mitochondrial oxidative stress increases under hyperlipidemic conditions, resulting in enhanced atherosclerotic plaque inflammation, necrotic core and fibrous cap remodeling, and susceptibility to rupture. ${ }^{20}$ In this study, ApoE-/- mice receiving methionine diet displayed high levels of serum Hcy, TC (Table 1), and typical atherosclerotic plaques, thereby causing accumulated lipid, increased necrotic core, ${ }^{17}$ decreased collagen fiber content, and infiltrated inflammation cells in the aortic root. After telmisartan treatment, these effects of HHcy were inhibited ${ }^{28}$ (Figs. 1-3). Consistent with the study by Schlimmer, our data revealed that telmisartan can effectively reduce oxidative stress in aortic tissue and subsequent peroxidation of membrane lipids, thereby preventing atherosclerosis formation. ${ }^{29}$ Based on these results, we speculated that Hcy might promote atherosclerosis formation via AT1R activation. Furthermore, lipid loading increased adventitial metalloproteinase-9 levels to promote cell migration. ${ }^{30}$ Intriguingly, we found that HHcy induced AFs migration and invasion in vitro and in vivo. Telmisartan also inhibited the migration and invasion of fibroblasts induced by HHcy (Figs. 5 and 8). Consistent with Dan Yao, ${ }^{9}$ Hcy promoted AT1R expression in AFs in a time- and concentration-dependent manner (Fig. 9). Hcy increased ROS production in AFs, increased $\mathrm{H}_{2} \mathrm{O}_{2}$ in cell supernatant, and promoted IL-6 and MMP9 expression in AFs (Figs. 6-7). ROS produced by NADPH oxidase is an important mediator in signal transduction. ${ }^{31}$ Cell migration in its essence is an invasive process that requires degradation of ECM through activation of matrix metalloproteinases (MMPs). ${ }^{31}$ Compelling evidence suggests that AT1R leads to ROS production. ${ }^{2}$ Moreover, ROS can directly or indirectly activate MMPs, hence inducing cell migration. These results suggest that Hcy may promote AFs migration and invasion by enhancing AT1R expression and then accelerate atherosclerosis formation. The development of atherosclerosis depends largely on local inflammation. A large number of macrophages in atherosclerotic lesions is an indicator of a more unstable and rupture-prone phenotype. ${ }^{32,33}$ In fact, these cells are aggregated in plaques and swallow lipids, become foam cells, and release cytokines and growth factors, as well as MMPs and ROS that degrade the structures of plaques to provide conditions for cell migration. ${ }^{34}$ Our 
study also showed that HHcy induced the infiltration of inflammatory cells in aortic root plaque and aortic adventitia inflammation in mice, which was consistent withLili et al. ${ }^{2}$ (Figs. 3-4). The results of mice aortic immunohistochemistry showed that infiltrations of MCP-1, IL-6, and Mac3 were mainly observed in the tunica adventitia of mice aorta. MCP-1 is a potent chemokine that stimulates cells migration. ${ }^{35}$ There is increasing evidence suggesting that Hcy has a possible role in triggering arterial inflammation. ${ }^{2,36,37}$ ERK-1/2 activation has strongly been shown to be associated with inflammation ${ }^{38,39}$ and atherosclerosis. ${ }^{40} \mathrm{~A}$ large number of studies have shown that ERK and PKC activation can promote cell migration and invasion. ${ }^{41,42}$ To further explore relevant mechanisms, AFs and HEK293A cells transfected with human AT1R were stimulated by Hcy, with or without telmisartan pretreatment for 1 hour, and the expression level of ERK-1/2 and PKC signaling pathway in AT1R was detected. Our results demonstrated that Hcy induced a robust and significant increase of ERK-1/2 and PKC phosphorylation, which was markedly attenuated by telmisartan (Figs. 11-12). These results clearly suggest the involvement of AT1R in mediating ERK-1/2 and PKC phosphorylation in Hcy.

Furthermore, our findings suggest that Hcy induces AT1R and ERK-1/2 and PKC activation. Activated ERK-1/2 and PKC further contribute to AFs proliferation, migration, and invasion and participate in the process of atherosclerosis by modulating MMP-9.

\section{Conclusion}

In conclusion, our experiments confirm that HHcy aggravates atherosclerosis formation, at least in part, by activating AFs through AT1R, causing AFs proliferation, migration, and invasion. These findings suggest that strategies designed to block AT1R may reduce HHcy-related adventitial migration and invasion and thus reduce HHcy-related vascular diseases.

\section{Abbreviations}




\begin{tabular}{|c|c|}
\hline Hcy & homocysteine \\
\hline HHcy & hyperhomocysteinemia \\
\hline AFs & adventitia fibroblasts \\
\hline AT1R & angiotensin II type 1 receptor \\
\hline Apoe-/- & apolipoprotein E gene-deficient mice \\
\hline IL-6 & interleukin-6 \\
\hline MCP-1 & monocyte chemoattractant protein-1 \\
\hline Mac3 & macrophages \\
\hline $\mathrm{H}_{2} \mathrm{O}_{2}$ & hydrogen peroxide \\
\hline ROS & reactive Oxygen Species \\
\hline MMP-9 & matrix metalloproteinase \\
\hline PKC & protein kinase $c$ \\
\hline ERK1/2 & extracellular signal-regulated protein kinases 1 and 2 \\
\hline ECM & extracellular matrix \\
\hline Telmi & telmisartan \\
\hline SD & sprague dawley \\
\hline SBP & systolic blood pressure \\
\hline TG & triglyceride \\
\hline TC & total cholesterol \\
\hline LDL & low-density lipoprotein \\
\hline HDL & high-density lipoprotein \\
\hline SEM & standard error of the mean \\
\hline
\end{tabular}

\section{Declarations}

\section{Ethics approval and consent to participate}

All animal experiments were approved by the Institutional Animal Care and Use Committee (No: YKD2015110) of Inner Mongolia Medical University, Hohhot, China and was conducted in accordance with the Guide for the Care and Use of laboratory animals from the National Institutes of Health (Bethesda, MD, USA). 
Not applicable

\section{Availability of data and material}

The dataset used and/ or analyzed during the current study are available from the corresponding author on reasonable request.

\section{Competing interests}

The authors have declared that no competing interests exist.

\section{Funding}

The research was supported by the National Natural Science Foundation of China (81560082).

\section{Authors' contributions}

ZBZ designed the experiments, carried out the experiments and wrote the manuscript; $X Y H$ and TXL wrote the manuscript; JQG designed the experiments, wrote the manuscript and revised the manuscript. All authors have read and approved the manuscript.

\section{Acknowledgements}

We were grateful for the technical support and kind provision of HEK293A cells by the Inner Mongolia Medical University Laboratory.

\section{References}

1. Li T, Yu B, Liu Z, et al. Homocysteine directly interacts and activates the angiotensin II type I receptor to aggravate vascular injury. Nat Commun. 2018;9:11.

2. Liu Z, Luo H, Zhang L, et al. Hyperhomocysteinemia exaggerates adventitial inflammation and angiotensin II-induced abdominal aortic aneurysm in mice. Circ Res. 2012;111:1261-1273.

3. Sun W, Pang Y, Liu Z, et al. Macrophage inflammasome mediates hyperhomocysteinemiaaggravated abdominal aortic aneurysm. J Mol Cell Cardiol. 2015;81:96-106.

4. Zhang D, Chen Y, Xie X, et al. Homocysteine activates vascular smooth muscle cells by DNA demethylation of platelet-derived growth factor in endothelial cells. J Mol Cell Cardiol. 2012;53:487496.

5. Duan H, Li Y, Yan L, et al. MicroRNA-217 suppresses homocysteine-induced proliferation and migration of vascular smooth muscle cells via N-methyl-D-aspartic acid receptor inhibition. Clin Exp Pharmacol Physiol. 2016;43: 967-975. 
6. Kaschina E, Unger T. Angiotensin AT1/AT2 receptors: regulation, signalling and function. Blood Press. 2003;12:70-88.

7. Kassab S, Garadah T, Abu-Hijleh M, et al. The angiotensin type 1 receptor antagonist valsartan attenuates pathological ventricular hypertrophy induced by hyperhomocysteinemia in rats. J Renin Angiotensin Aldosterone Syst. 2006;7:206-211.

8. Tiyerili V, Mueller CF, Becher UM, et al. Stimulation of the AT2 receptor reduced atherogenesis in ApoE(-/-)/AT1A(-/-) double knock out mice. J Mol Cell Cardiol. 2012;52:630-637.

9. Yao D, Sun NL. Hyperhomocysteinemia accelerates collagen accumulation in the adventitia of balloon-injured rat carotid arteries via angiotensin II type 1 receptor. Int J Mol Sci. 2014;15:1948719498.

10. Siow RC, Mallawaarachchi CM, Weissberg PL. Migration of adventitial myofibroblasts following vascular balloon injury: insights from in vivo gene transfer to rat carotid arteries. Cardiovasc Res. 2003;59:212-221.

11. Zou T, Yang W, Hou Z, Yang J. Homocysteine enhances cell proliferation in vascular smooth muscle cells: role of p38 MAPK and p47phox. Acta Biochim Biophys Sin (Shanghai). 2010;42:908-915.

12. Xu L, Hao H, Hao Y, et al. Aberrant MFN2 transcription facilitates homocysteine-induced VSMCs proliferation via the increased binding of c-Myc to DNMT1 in atherosclerosis. J Cell Mol Med. 2019;23:4611-4626.

13. Xu F, Liu Y, Shi L, et al. NADPH oxidase p47phox siRNA attenuates adventitial fibroblasts proliferation and migration in apoE(-/-) mouse. J Transl Med. 2015;13:38.

14. Sen U, Herrmann M, Herrmann W, Tyagi SC. Synergism between AT1 receptor and hyperhomocysteinemia during vascular remodeling. Clin Chem Lab Med. 2007;45:1771-1776.

15. Kim H, Kim SH, Hwang D, et al. Extracellular pyruvate kinase M2 facilitates cell migration by upregulating claudin-1 expression in colon cancer cells. Biochem Cell Biol. 2019.

16. Neuman I, Cooke M, Lemiña NA, Kazanietz MG, Cornejo MF. 5-oxo-ETE activates migration of H295R adrenocortical cells via MAPK and PKC pathways. Prostaglandins Other Lipid Mediat. 2019;144:106346.

17. Xiaoling Y, Li Z, ShuQiang L, et al. Hyperhomocysteinemia in ApoE-/- mice leads to overexpression of enhancer of zeste homolog 2 via miR-92a regulation. PLoS One. 2016;11:e0167744.

18. Yang AN, Zhang HP, Sun Y, et al. High-methionine diets accelerate atherosclerosis by HHcy-mediated FABP4 gene demethylation pathway via DNMT1 in ApoE(-/-) mice. FEBS Lett. 2015;589:3998-4009.

19. Xu JY, Chang NB, Li T, et al. Endothelial Cells Inhibit the Angiotensin II Induced Phenotypic Modulation of Rat Vascular Adventitial Fibroblasts. J Cell Biochem. 2017;118:1921-1927.

20. Vendrov AE, Stevenson MD, Alahari S, et al. Attenuated superoxide dismutase 2 activity induces atherosclerotic plaque instability during aging in hyperlipidemic mice. J Am Heart Assoc. 2017;6.

21. Venegas-Pino DE, Banko N, Khan MI, Shi Y, Werstuck GH. Quantitative analysis and characterization of atherosclerotic lesions in the murine aortic sinus. J Vis Exp. 2013:50933. 
22. He W M , Dai T, Chen J , et al. Leukocyte cell-derived chemotaxin 2 inhibits development of atherosclerosis in mice. ZR News. 2019; 40.

23. Lu YY, Chen TS, Qu JL, Pan WL, Sun L, Wei XB. Dihydroartemisinin (DHA) induces caspase-3dependent apoptosis in human lung adenocarcinoma ASTC-a-1 cells. J Biomed Sci. 2009;16:16.

24. Wang J, Liu G, Li Q, et al. Mucin1 promotes the migration and invasion of hepatocellular carcinoma cells via JNK-mediated phosphorylation of Smad2 at the C-terminal and linker regions. Oncotarget. 2015;6:19264-19278.

25. Snigireva AV, Vrublevskaya VV, Skarga YY, Morenkov OS. Cell surface heparan sulfate proteoglycans are involved in the extracellular Hsp90-stimulated migration and invasion of cancer cells. Cell Stress Chaperones. 2019;24:309-322.

26. Zhao MX, Wen JL, Wang L, Wang XP, Chen TS. Intracellular catalase activity instead of glutathione level dominates the resistance of cells to reactive oxygen species. Cell Stress Chaperones. 2019;24:609-619.

27. Wierda RJ, Rietveld IM, van Eggermond MC, et al. Global histone H3 lysine 27 triple methylation levels are reduced in vessels with advanced atherosclerotic plaques. Life Sci. 2015;129:3-9.

28. Chan YK, El-Nezami H, Chen Y, Kinnunen K, Kirjavainen PV. Probiotic mixture VSL\#3 reduce high fat diet induced vascular inflammation and atherosclerosis in ApoE(-/-) mice. AMB Express. 2016;6:61.

29. Schlimmer N, Kratz M, Böhm M, Baumhäkel M. Telmisartan, ramipril and their combination improve endothelial function in different tissues in a murine model of cholesterol-induced atherosclerosis. $\mathrm{Br}$ J Pharmacol. 2011;163:804-814.

30. Kokkinopoulos I, Wong MM, CMF P, et al. Adventitial SCA-1+ progenitor cell gene sequencing reveals the mechanisms of cell migration in response to hyperlipidemia. Stem Cell Rep. 2017;9:681-696.

31. San MA, Griendling KK. Redox control of vascular smooth muscle migration. Antioxid Redox Signal. 2010;12:625-640.

32. Narula J, Garg P, Achenbach S, Motoyama S, Virmani R, Strauss HW. Arithmetic of vulnerable plaques for noninvasive imaging. Nat Clin Pract Cardiovasc Med. 2008;5:S2-S10.

33. Jaffer FA, Libby P, Weissleder R. Molecular and cellular imaging of atherosclerosis: emerging applications. J Am Coll Cardiol. 2006;47:1328-1338.

34. Libby P. Inflammation in atherosclerosis. 2002;420:868-874.

35. Wang G, Siow YL, O K. Homocysteine stimulates nuclear factor kappaB activity and monocyte chemoattractant protein-1 expression in vascular smooth-muscle cells: a possible role for protein kinase C. Biochem J. 2000;352:817-826.

36. Yun J, Kim JY, Kim OY, et al. Associations of plasma homocysteine level with brachial-ankle pulse wave velocity, LDL atherogenicity, and inflammation profile in healthy men. Nutr Metab Cardiovasc Dis. 2011;21:136-143.

37. Lentz SR. Mechanisms of homocysteine-induced atherothrombosis. J Thromb Haemost. 2005;3:1646-1654. 
38. Morel JC, Park CC, Zhu K, Kumar P, Ruth JH, Koch AE. Signal transduction pathways involved in rheumatoid arthritis synovial fibroblast interleukin-18-induced vascular cell adhesion molecule-1 expression. J Biol Chem. 2002;277:34679-34691.

39. Li XD, Hong MN, Chen J, et al. Adventitial fibroblast-derived vascular endothelial growth factor promotes vasa vasorum-associated neointima formation and macrophage recruitment. Cardiovasc Res. 2020;116:708-720.

40. Tharaux PL, Chatziantoniou C, Fakhouri F, Dussaule JC. Angiotensin II activates collagen I gene through a mechanism involving the MAP/ER kinase pathway. Hypertension. 2000;36:330-336.

41. Liao YH, Hsu SM, Yang HL, Tsai MS, Huang PH. Upregulated ankyrin repeat-rich membrane spanning protein contributes to tumour progression in cutaneous melanoma. $\mathrm{Br} J$ Cancer. 2011;104:982-988.

42. Song H, Moon A. Glial cell-derived neurotrophic factor (GDNF) promotes low-grade Hs683 glioma cell migration through JNK, ERK-1/2 and p38 MAPK signaling pathways. Neurosci Res. 2006;56:29-38.

\section{Tables}

Table 1. Hcy and lipid values of three groups

\begin{tabular}{lccccc}
\hline & Hcy & TG & TC & LDL & HDL \\
& $(\mu \mathrm{mol} / \mathrm{L})$ & $(\mu \mathrm{mol} / \mathrm{L})$ & $(\mu \mathrm{mol} / \mathrm{L})$ & $(\mu \mathrm{mol} / \mathrm{L})$ & $(\mu \mathrm{mol} / \mathrm{L})$ \\
& & & & & \\
\hline Control & $23.85 \pm 2.09$ & $1.07 \pm 0.53$ & $10.26 \pm 1.47$ & $3.03 \pm 0.57$ & $1.64 \pm 0.27$ \\
HHcy & $35.89 \pm 3.26^{*}$ & $1.21 \pm 0.36$ & $12.72 \pm 0.55^{*}$ & $3.61 \pm 0.72$ & $1.27 \pm 0.21^{*}$ \\
HHcy+Telmi & $17.32 \pm 3.94^{\#}$ & $0.88 \pm 0.28$ & $8.76 \pm 1.59^{\#}$ & $2.68 \pm 0.31^{\#}$ & $1.95 \pm 0.11^{\#}$
\end{tabular}

Hcy and lipid levels were measured in five to seven mice per group. Data represent mean $\pm \mathrm{SD}$. ${ }^{*} \mathrm{P}<0.05$ compared to Control group; ${ }^{\#} \mathrm{P}<0.05$ compared to HHcy group.

Control, standard mouse diet group; HHcy, 1.5\% methionine group; HHcy+Telmi, HHcy + telmisartan treatment group; HHcy, homocysteinemia; TG, triglyceride; TC, total cholesterol; LDL, low-density lipoprotein; HDL, highdensity lipoprotein.

Table 2. Systolic blood pressure and weight of three groups 


\begin{tabular}{llll}
\hline & Control & HHcy & HHcy+Telmi \\
\hline Weight $(\mathrm{g})$ & 26.73 & 28.66 & 25.89 \\
& \pm 0.91 & \pm 1.29 & \pm 1.29 \\
& & & \\
& & 125 & 121 \\
SBP before treatment (mmHg) & 119 & & \\
& \pm 4.97 & \pm 10.29 & \pm 9.01 \\
SBP after treatment (mmHg) & 120 & 121 & 113 \\
& & & \pm 7.05 \\
\hline
\end{tabular}

SBP and weight were measured in five to seven mice per group. Data represent mean \pm SD.

Control, standard mouse diet group; HHcy, 1.5\% methionine group; HHcy+Telmi, HHcy + telmisartan treatment group; SBP, systolic blood pressure. SBP before treatment: the systolic blood pressure of mice without $1.5 \%$ methionine diet and telmisartan gavage. SBP after treatment: the systolic blood pressure of mice underwent 12 consecutive weeks after receiving 1.5\% methionine diet and telmisartan gavage.

\section{Figures}
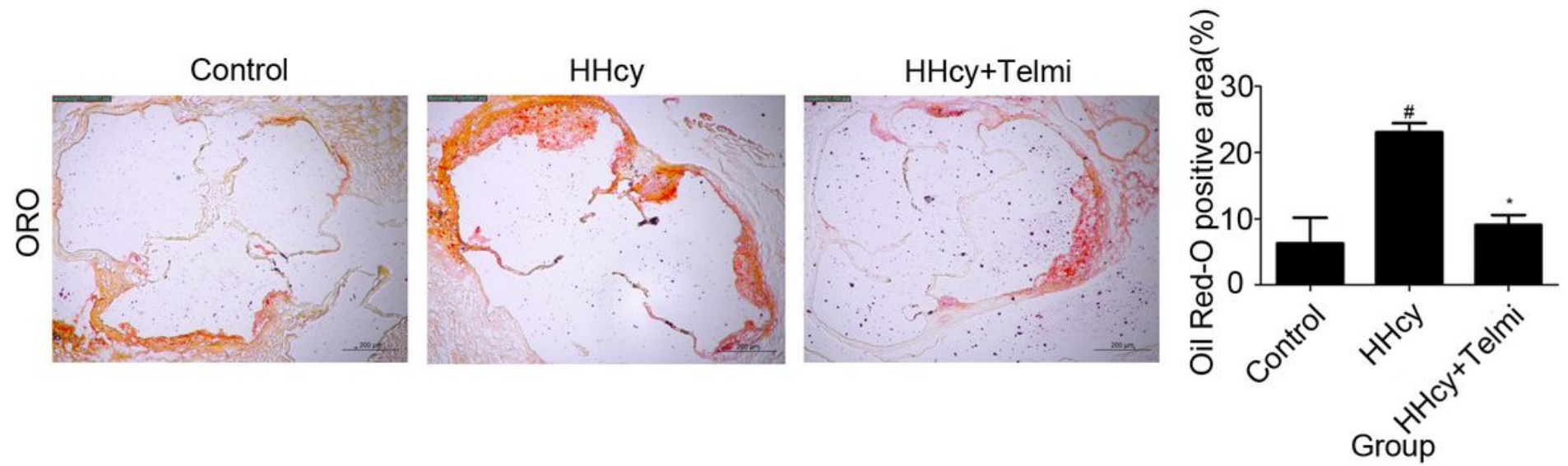

Figure 1

Hcy accelerates atherosclerosis formation (a) Representative Oil Red 0 staining of the thoracic aorta root sections. (b) Quantification of the average plaque area was performed using the Image-Pro Plus software. The plaque area was presented as lesion \% (\% of whole aorta) ( $n=6$ sections per mice). Scale bars $=100.1 \mu \mathrm{m}$. Magnification: $\times 100$. The data were analyzed by one-way ANOVA. Data represent mean 
\pm SEM. $\mathrm{n}=3$ mice for each group. \#P $<0.05$ versus control; ${ }^{*} \mathrm{P}<0.05$ versus $\mathrm{HHcy}$. Control, standard mouse diet group; HHcy, 1.5\% methionine group, HHcy+Telmi: HHcy + telmisartan treatment group.

a

Control

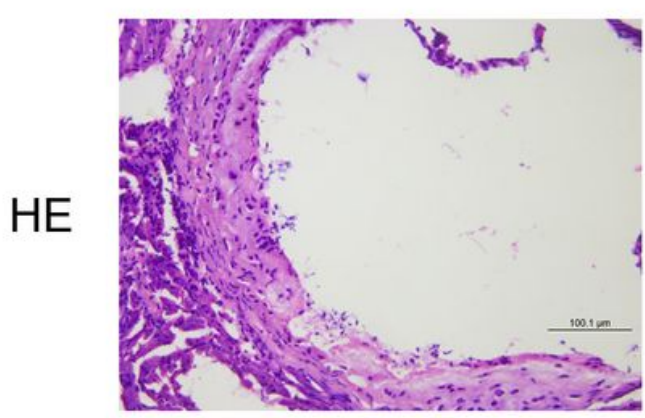

b

C

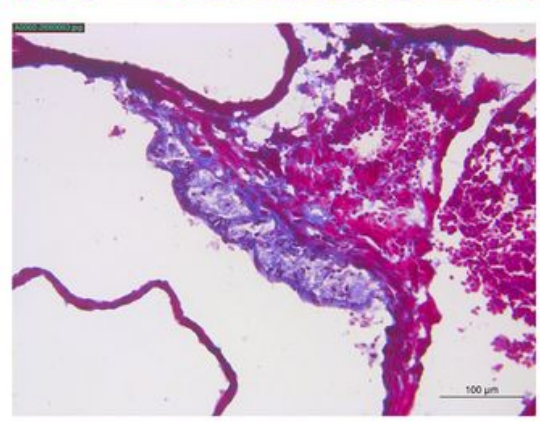

HHcy
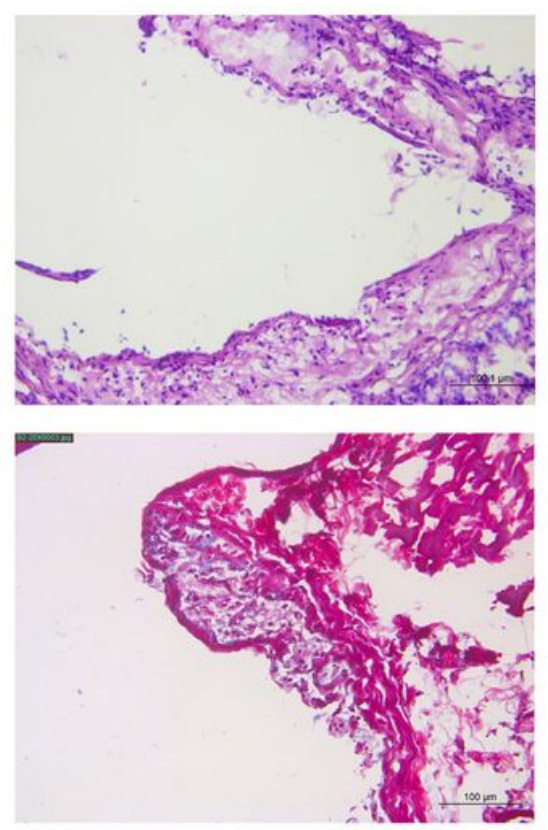

HHcy+Telmi
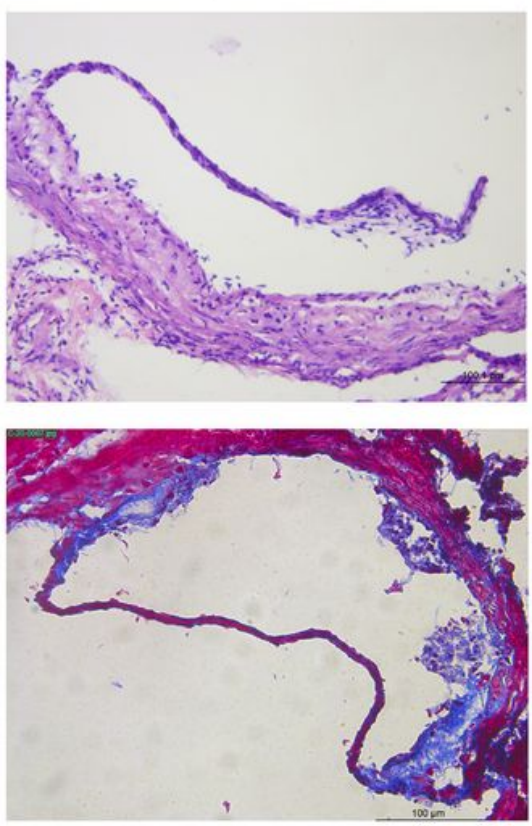

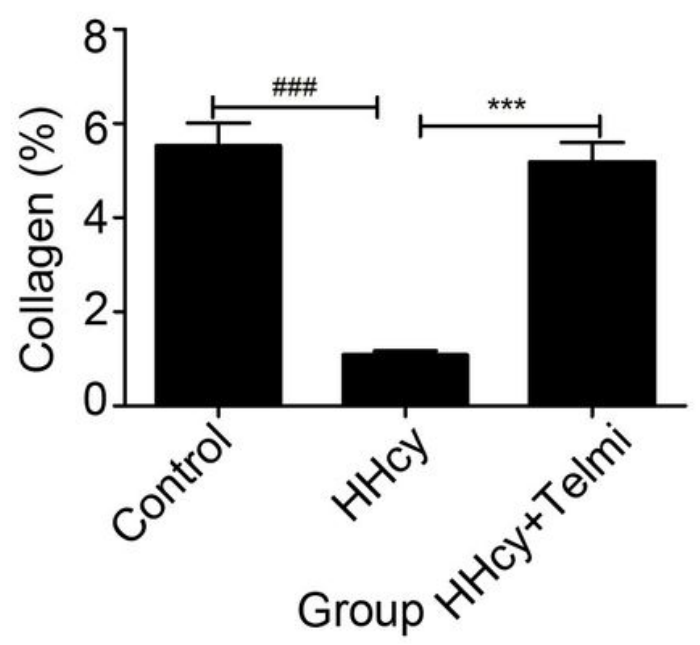

Figure 2

HHcy increases features of plaque instability (a) Representative H\&E staining. Magnification: $\times 200$. Scale bars $=100.1 \mu \mathrm{m}$. (b) Representative Masson staining. Collagen fibers showed as blue. Magnification: $\times 200$. Scale bars $=100 \mu \mathrm{m}$. (c) Total collagen fibers quantification. The percent of the positively stained area to to the measured visual field area was reported, collagen content analysis was carried out using Image J software. Values represent mean $\pm \mathrm{SEM}, \mathrm{n}=3$ mice for each group. The data were analyzed by one-way ANOVA. \#\#\#P $<0.001$ versus control; ***P $<0.001$ versus HHcy. Control, standard mouse diet group; HHcy, 1.5\% methionine group, HHcy+Telmi: HHcy + telmisartan treatment group. 
a
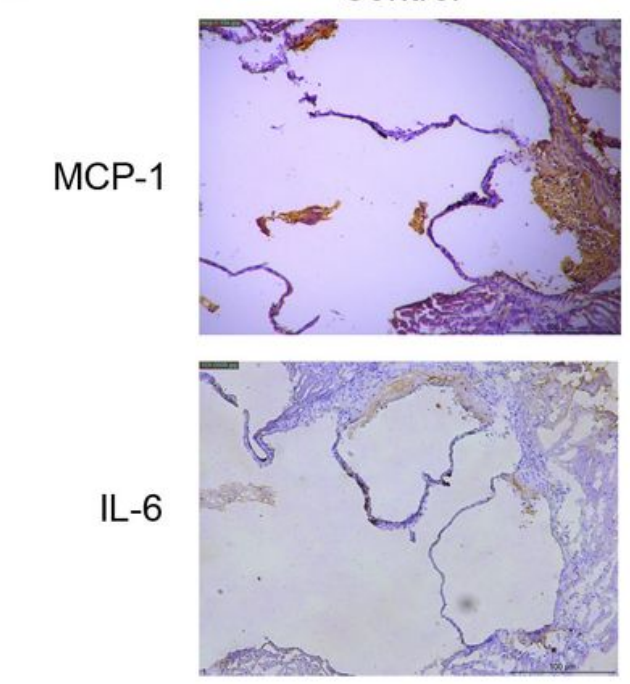

MAC3

b

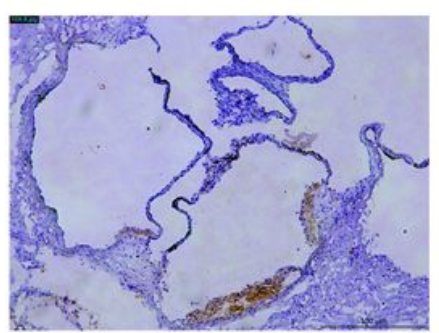

MCP-1

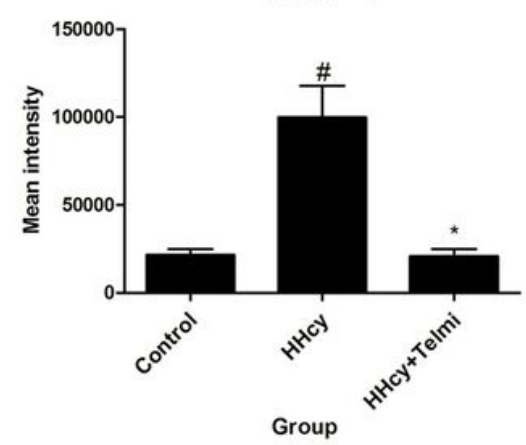

HHcy
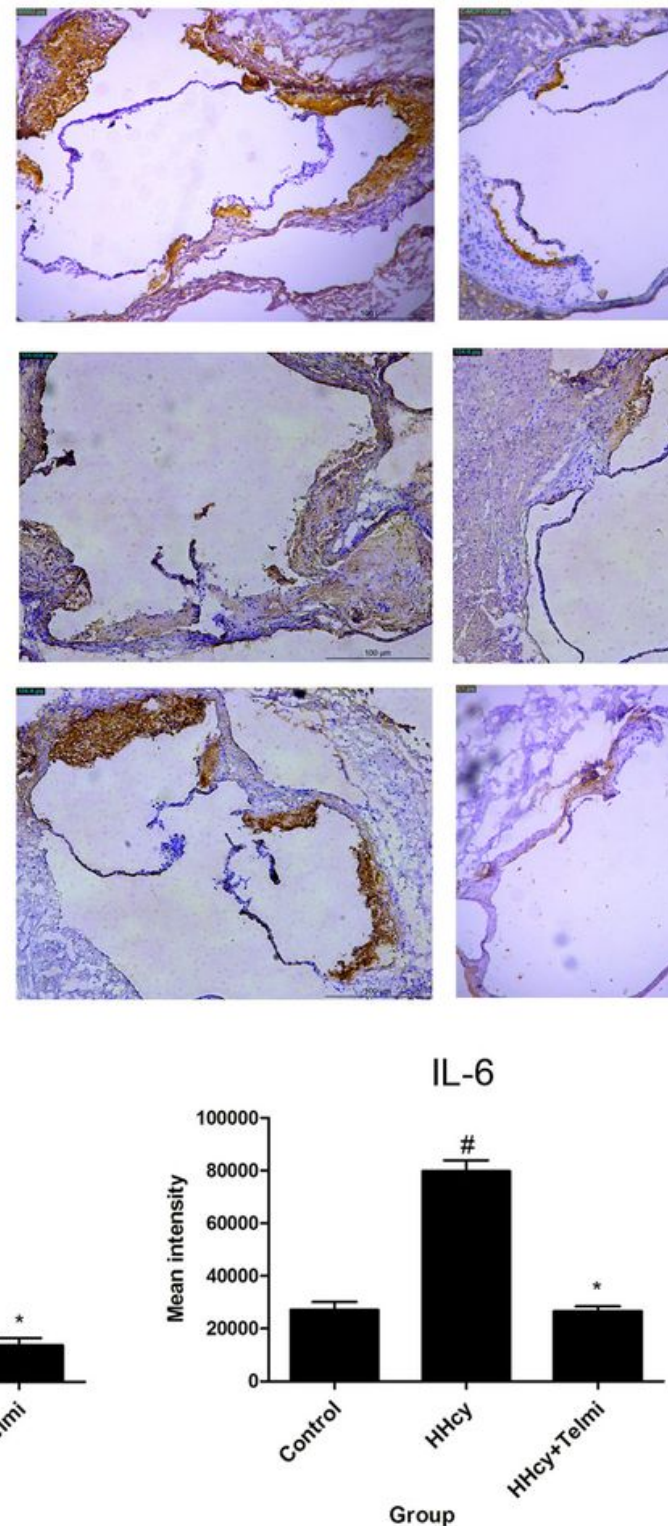

Group
HHcy+Telmi
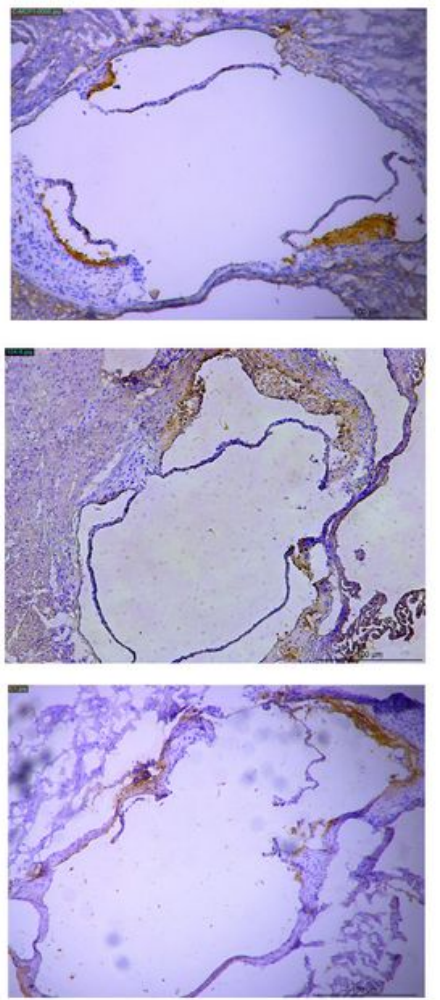

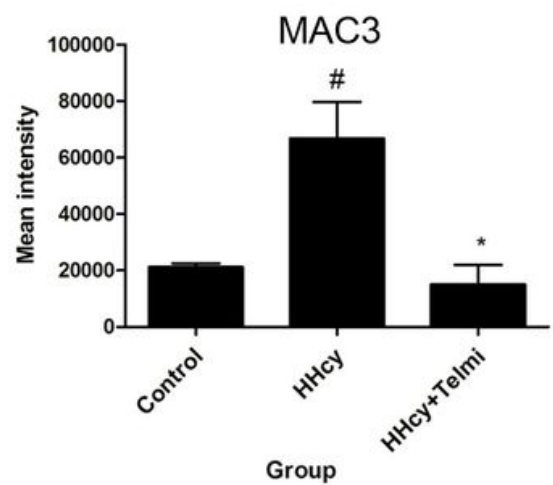

\section{Figure 3}

HHcy promoted inflammation of plaques in ApoE-/- male mice (a) Immunohistochemical staining shows MCP-1, IL-6, and Mac3 expression in each group. Scale bar = 100 $\mu \mathrm{m}$. Magnification: $\times 100$. (b)

Quantitative analysis of MCP-1, IL-6, and Mac-3 infiltration in atherosclerotic plaques of aortic roots. $n=3$ mice for each group. Data represent mean \pm SEM. The data were analyzed by one-way ANOVA. \#P $<0.05$ versus control; ${ }^{*} \mathrm{P}<0.05$ versus HHcy. Control, standard mouse diet group; HHcy, 1.5\% methionine group, HHcy+Telmi: HHcy + telmisartan treatment group; MCP-1, monocyte chemoattractant protein-1; IL-6, interleukin-6; Mac3, macrophages. 

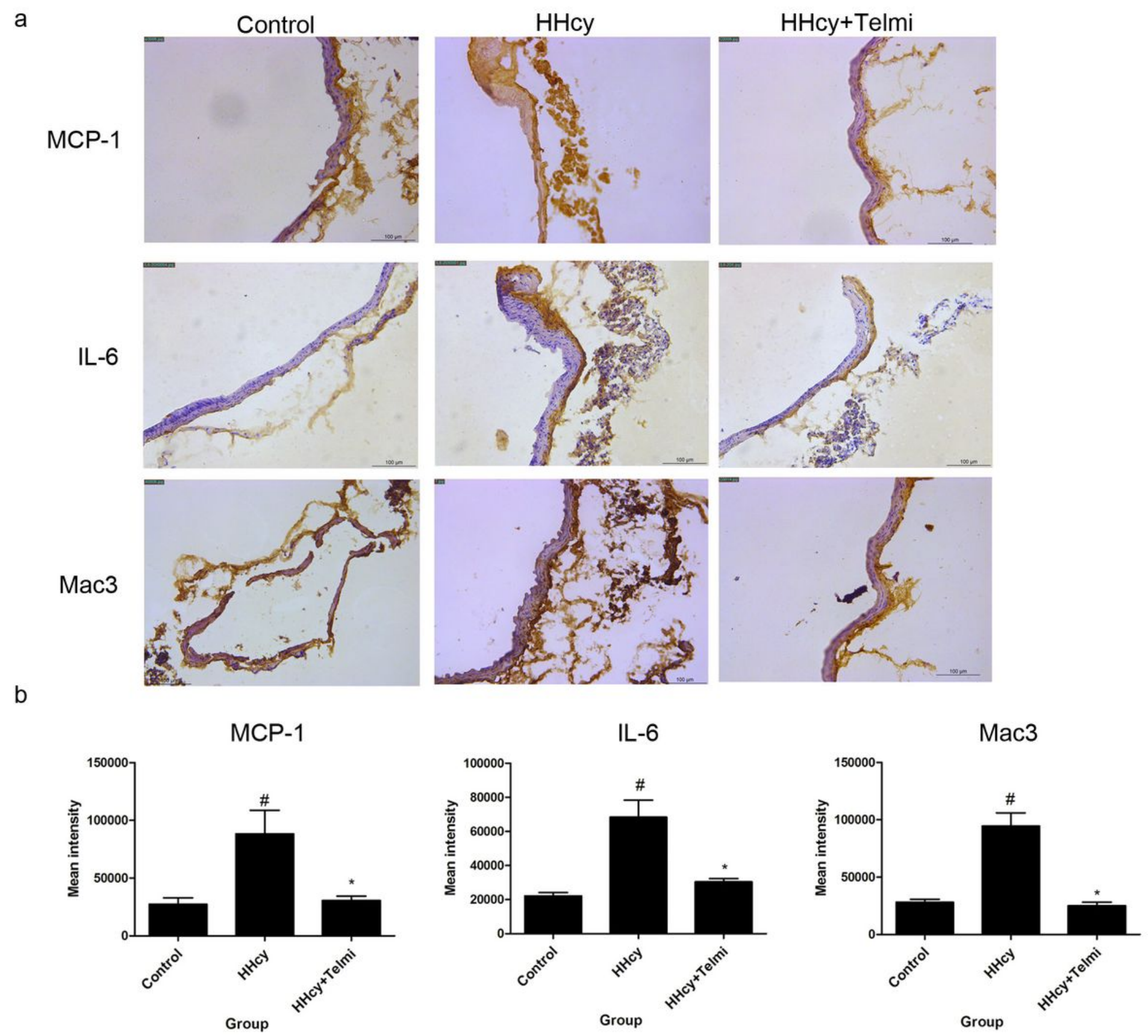

Figure 4

AT1R mediates HHcy-promoted inflammation of aortic adventitia in ApoE-/- male mice (a) Representative immunohistochemistry staining of IL-6, MCP-1, and Mac3 infiltration in aortic adventitia in ApoE-/- male mice. (b) Quantitative analysis of MCP-1, IL-6, and Mac3 infiltration in aortic adventitia. Scale bar = 100 $\mu \mathrm{m}$. Magnification: $\times 200 \mathrm{n}=3$ mice for each group. Data represent mean \pm SEM. The data were analyzed by one-way ANOVA. \#P <0.05 versus control; *P < 0.05 versus HHcy. Control, standard mouse diet group; HHcy, 1.5\% methionine group; HHcy+Telmi: HHcy + telmisartan treatment group. 
Control

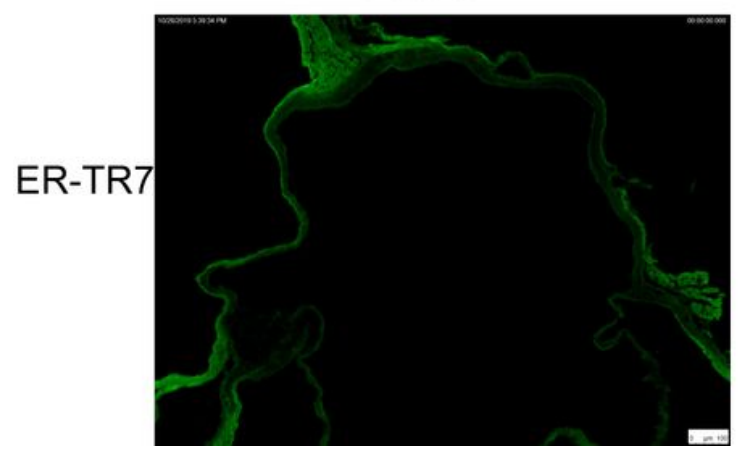

HHcy

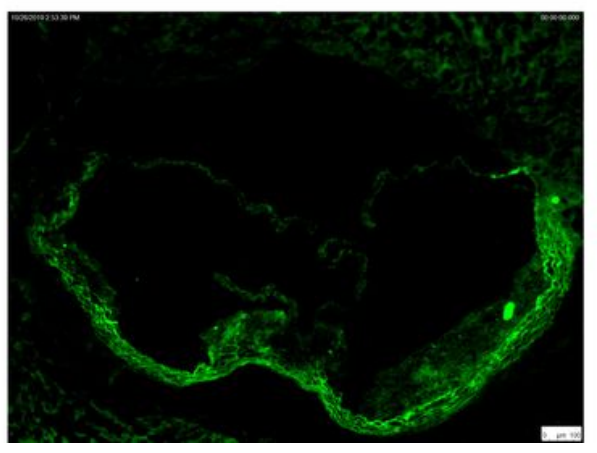

HHcy+Telmi

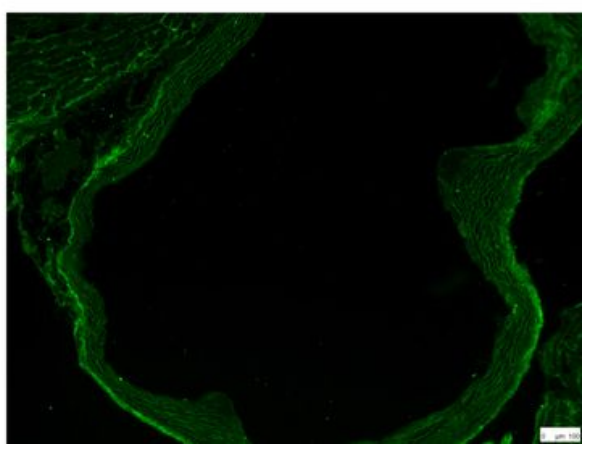

\section{Figure 5}

HHcy induces AFs migration and invasion Representative immunofluorescence staining. Control, few ERTR7 in adventitia of aorta root; HHcy, more ER-TR7 in the whole aortic wall and plaque; HHcy + Telmi, ERTR7 decreased after telmisartan treatment and was mainly expressed in adventitia of aorta. Scale bar $=$ $100 \mu \mathrm{m}$. Magnification: $\times 100$. Control, standard mouse diet group; HHcy, 1.5\% methionine group; HHcy+Telmi, HHcy + telmisartan treatment group.

a

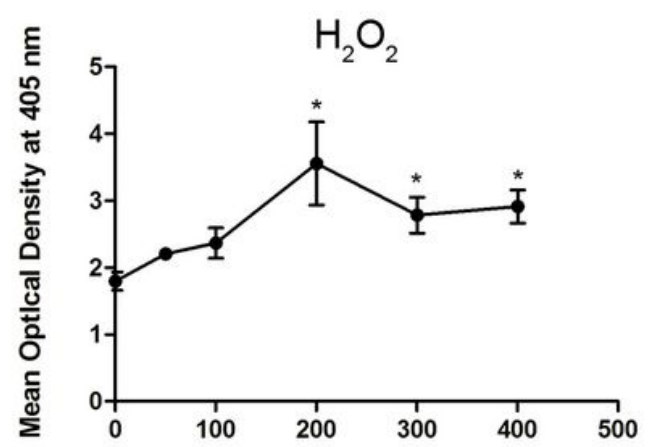

C

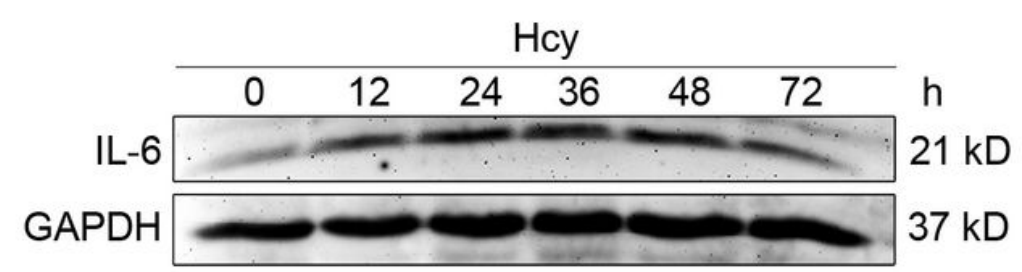

b
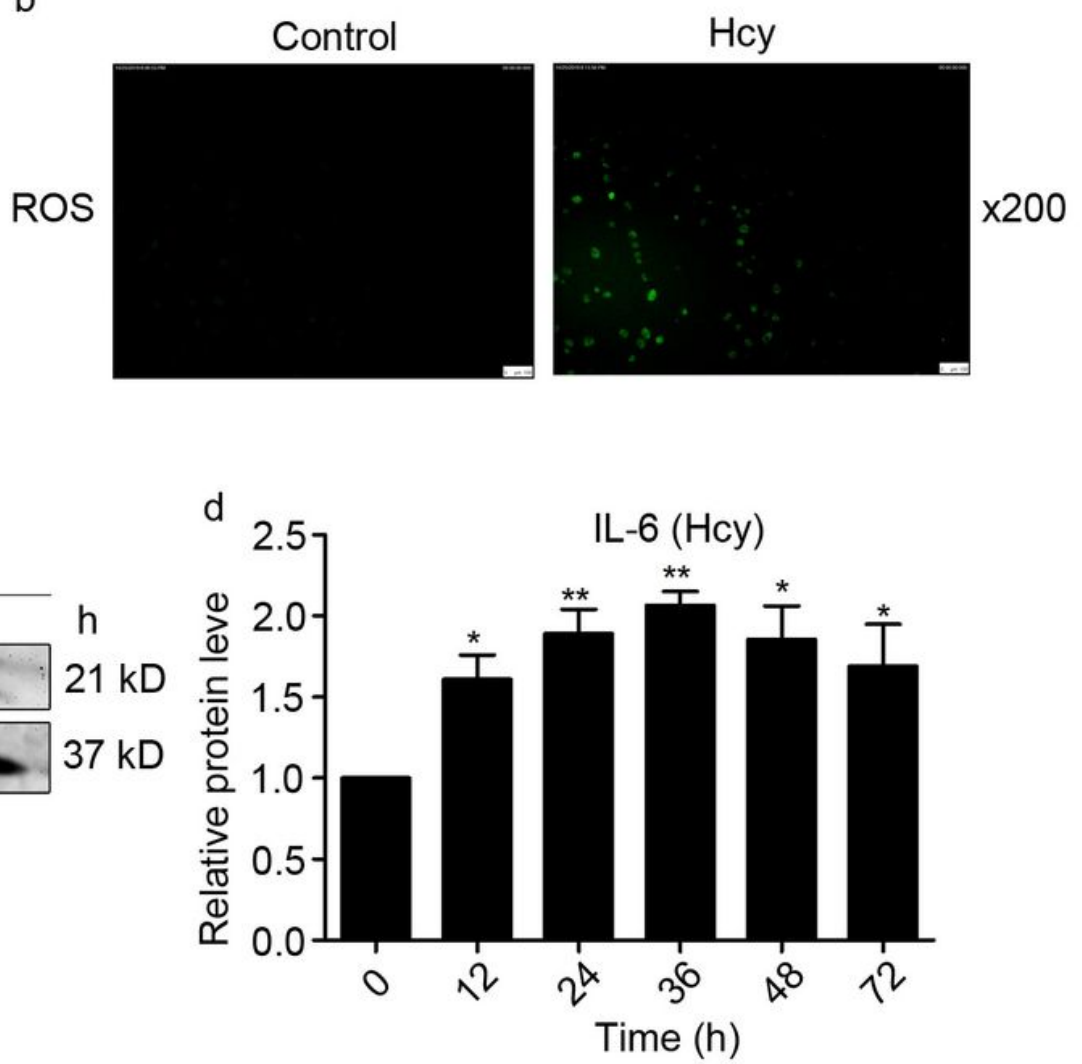

Figure 6

HHcy induces inflammation in AFs (a)The concentration of $\mathrm{H} 2 \mathrm{O} 2$ in the cell supernatant was measured by a hydrogen peroxide kit. (b) Fluorescence microscopy showed that the green fluorescence detected by the ROS probe DCFH-DA was brighter in the Hcy group than the control group, when the cells treated with $200 \mu \mathrm{mol} / \mathrm{L}$ Hcy were incubated for 48 hours. (c) Western blot indicated IL-6 levels in cells treated with 
$200 \mu \mathrm{mol} / \mathrm{L}$ Hcy in different periods of time. (d) Densitometric analysis of IL-6 was performed against $\operatorname{GAPDH}(n=3)$. Data represent mean \pm SEM. The data were analyzed by one-way ANOVA. ${ }^{*}<<0.05$ versus 0 hour. ${ }^{*} \mathrm{P}<0.01$ versus 0 hour. Figure b: Control, untreated cells; Hcy: cells treated with 200 $\mu \mathrm{mol} / \mathrm{L}$ Hcy, h: hour.

a

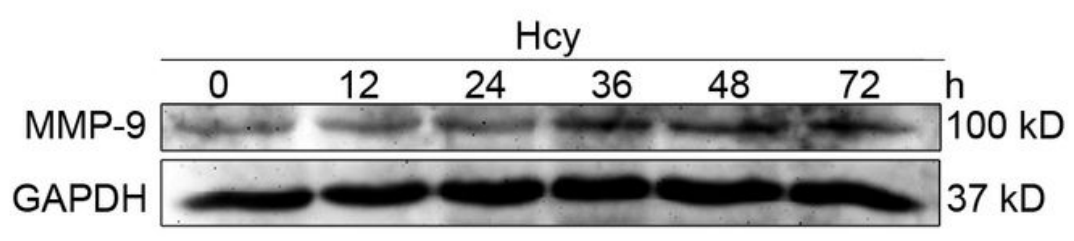

b

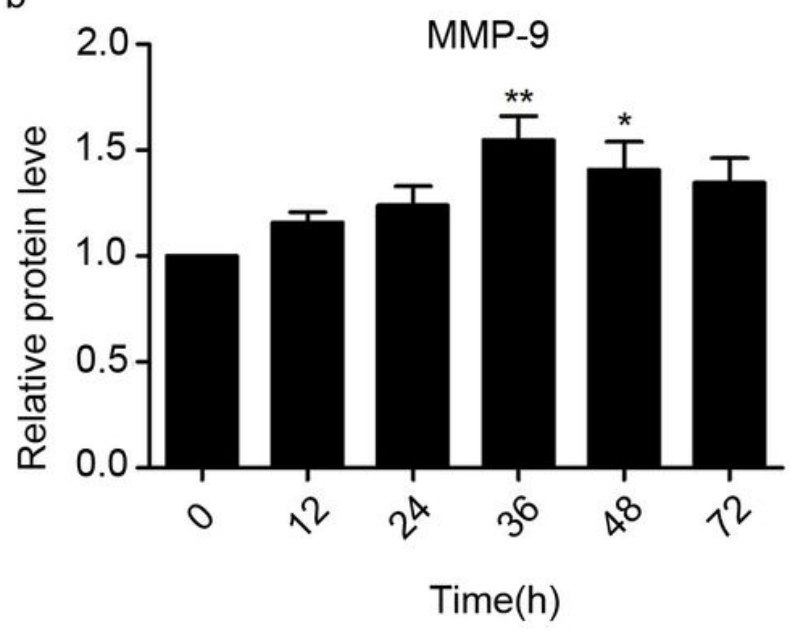

Figure 7

Hcy induces MMP-9 expression in AFs (a) Western blot indicated MMP-9 levels in cells treated with 200 $\mu \mathrm{mol} / \mathrm{L}$ Hcy in different periods of time. (b) Densitometric analyses of MMP-9 was performed against GAPDH $(n=3)$. Data represent mean \pm SEM. The data were analyzed by one-way ANOVA. ${ }^{P}<0.05$ versus 0 hour; ${ }^{\star \star} P<0.01$ versus 0 hour, $h$ : hour. 


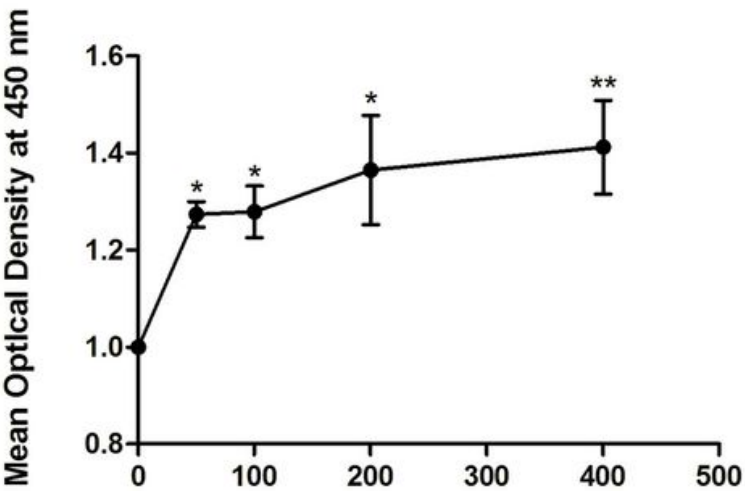

Hcy $(\mu \mathrm{mol} / \mathrm{L})$

b
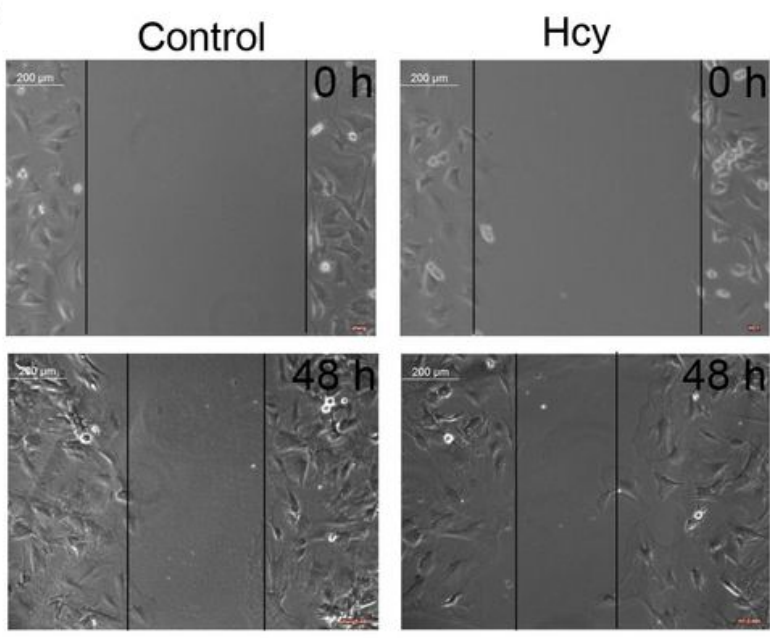

d

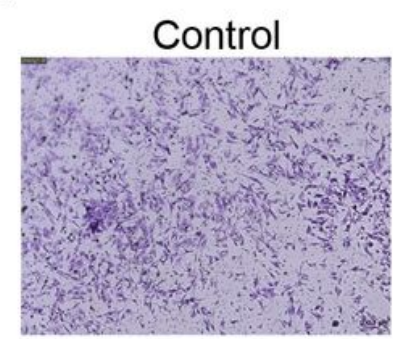

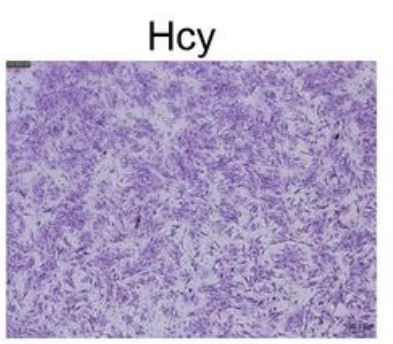

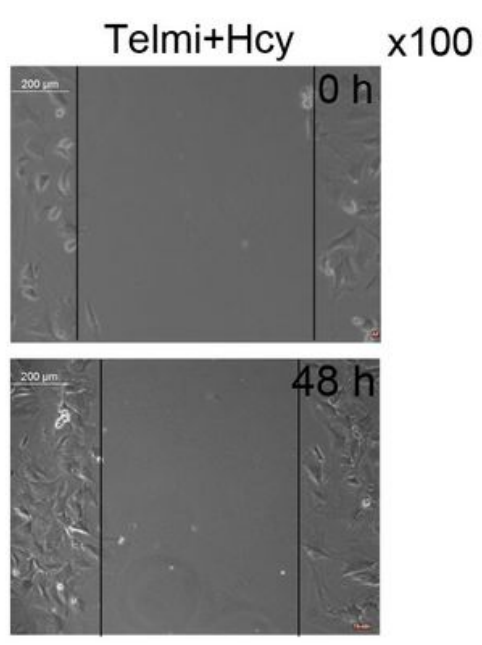

c

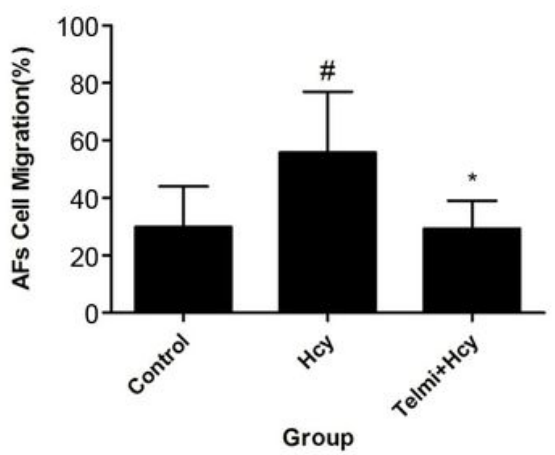

e

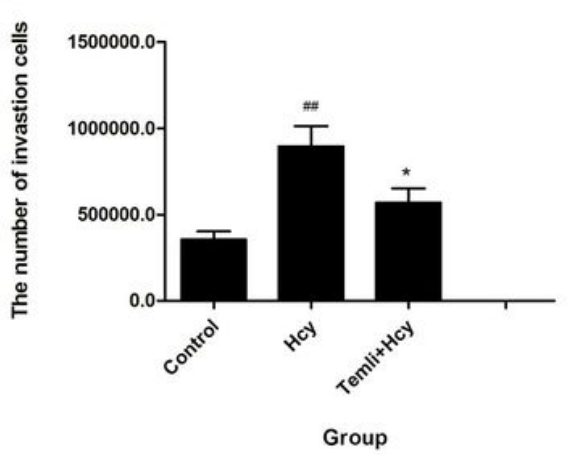

\section{Figure 8}

Hcy induces AFs migration and invasion via AT1R (a) Cell viability was determined by Cell Counting Kit-8. Cells were treated with $\mathrm{Hcy}(0,50,100,200$, and $400 \mu \mathrm{mol} / \mathrm{L})$ for 48 hours. (b) Cells were scratched and treated with $200 \mu \mathrm{mol} / \mathrm{L}$ Hcy for 48 hours. An image of the wound closure area. Scale bars $=200 \mu \mathrm{m}$, magnification: $\times 100$. (c) Quantification of the wound closure area was performed using the Image-Pro Plus software. $(d)$ The cells $(1 \times 105$ cells/well) were seeded in invasion chambers after Hcy treatment for 48 hours. Cells were stained with crystal violet. Scale bars $=100.1 \mu \mathrm{m}$, magnification: $\times 40$. (e) The quantification of invasion. $n=3$. Data represent mean \pm SEM. The data were analyzed by one-way 
ANOVA if the data that failed to pass the normality test were analyzed by nonparametric test. \#P $<0.05$ versus control; ${ }^{*} \mathrm{P}<0.05$ versus Hcy; ${ }^{\star \star} \mathrm{P}<0.01$. Control, untreated cells; Hcy, cells treated with 200 $\mu \mathrm{mol} / \mathrm{L}$ Hcy; Hcy+Telmi: telmisartan pretreatment group.

a

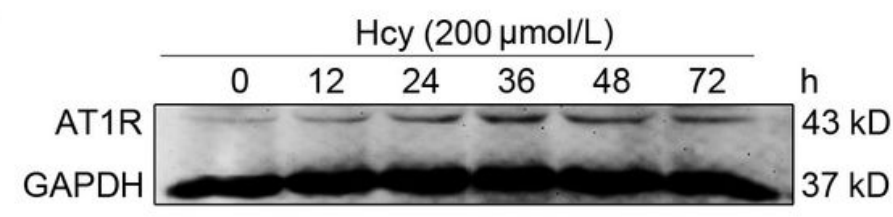

c

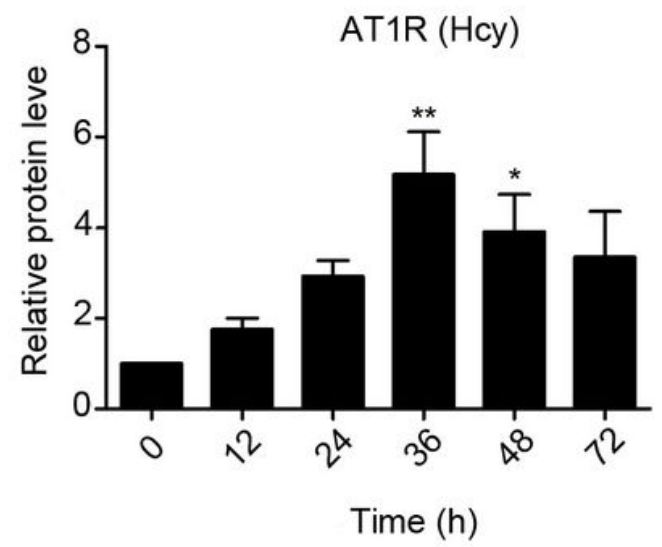

b

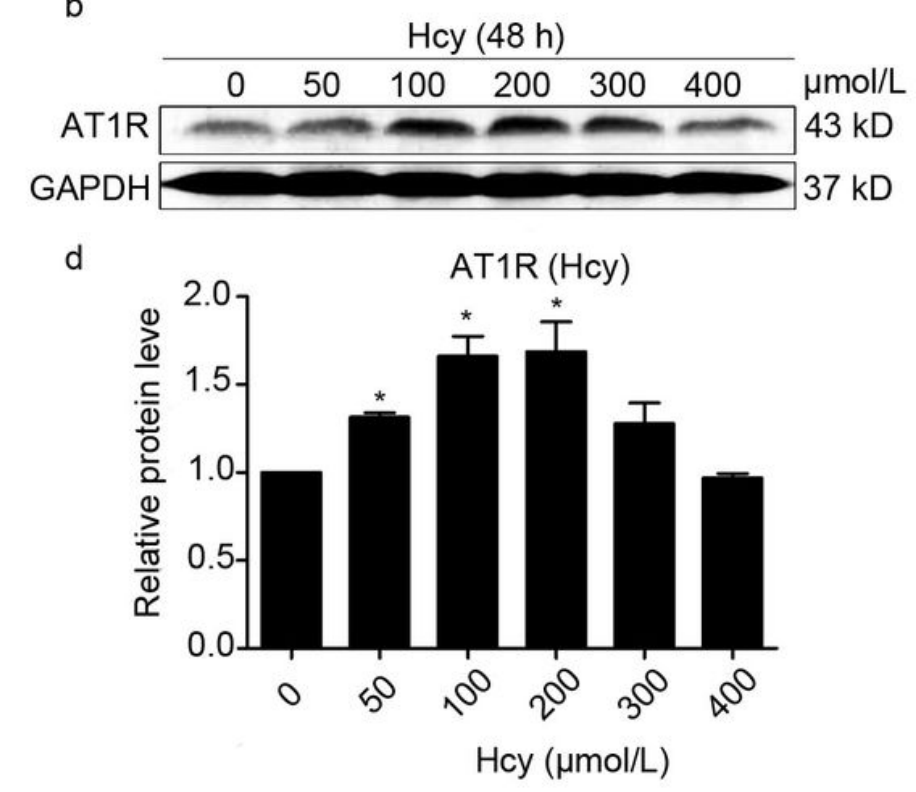

e

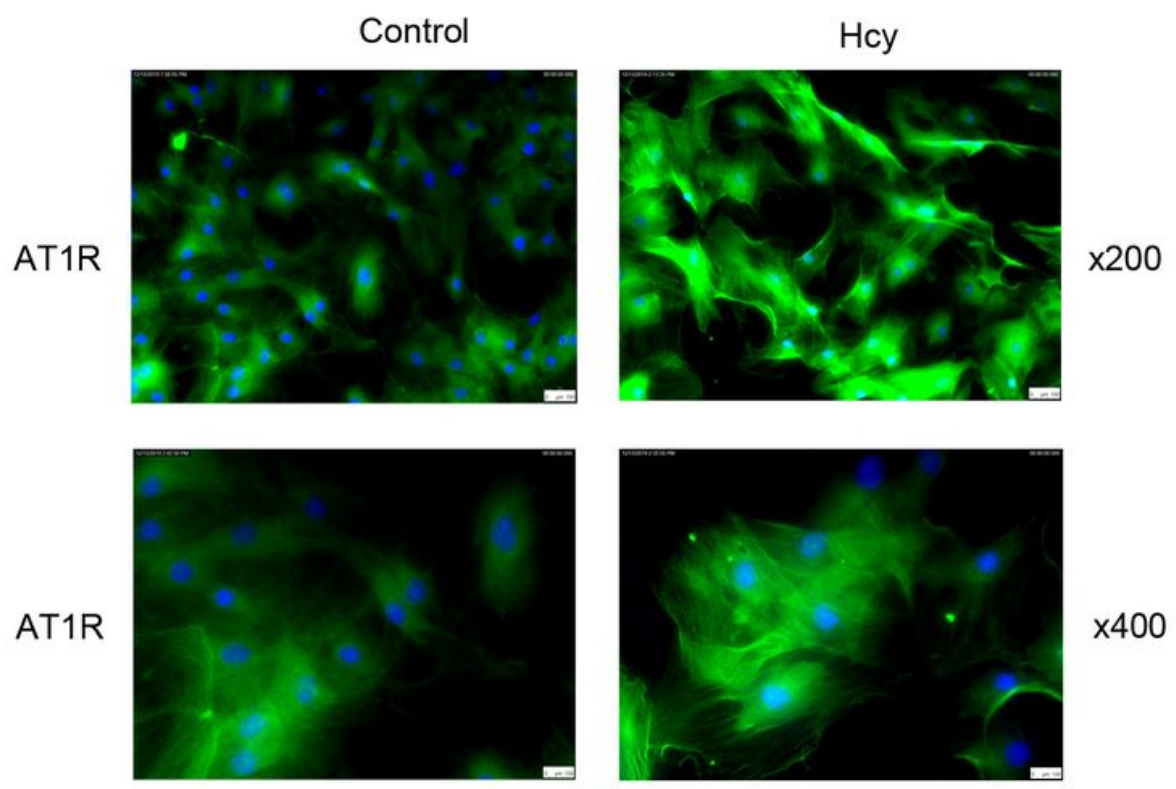

\section{Figure 9}

Hcy induces AT1R expression in AFs (a) Western blot indicated AT1R levels in AFs treated with 200 $\mu \mathrm{mol} / \mathrm{L}$ Hcy in different periods of time $(\mathrm{n}=3)$. (b) Western blot indicated that AT1R levels in AFs were treated with various doses of Hcy $(0$ to $400 \mu \mathrm{mol} / \mathrm{L})$ for 48 hours $(n=3)$. (c, d) Densitometric analyses of AT1R were performed against GAPDH. Data represent mean \pm SEM. The data were analyzed by one-way ANOVA. $* * P<0.01$ compared with 0 or control. h: hour. (e) Fluorescence microscopy showed that the green fluorescence detected at 48 hours incubation was much brighter in the Hcy group than in the control group. Scale bar $=100 \mu \mathrm{m}$, magnification: $\times 100$ or $\times 200$. 
a

Hcy

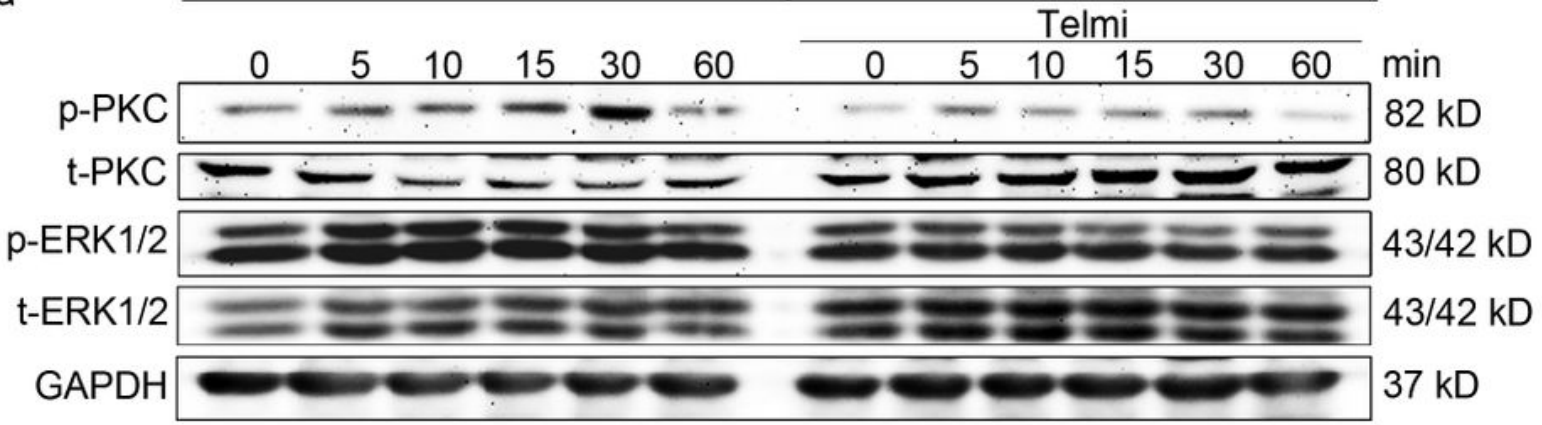

b

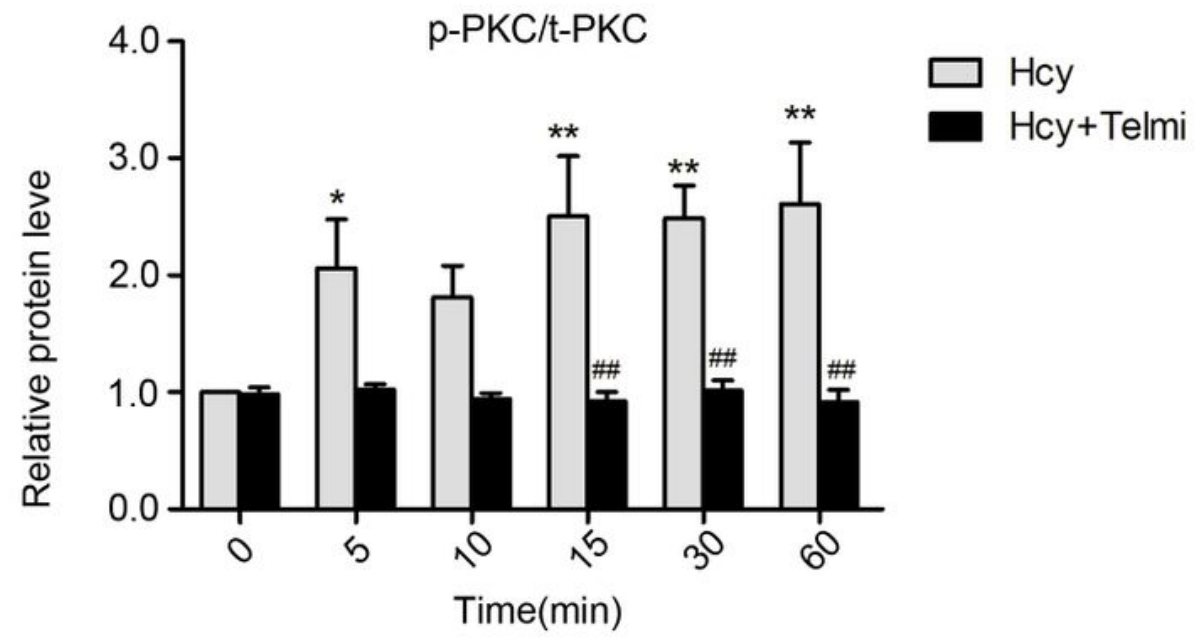

C

p-ERK/t-ERK

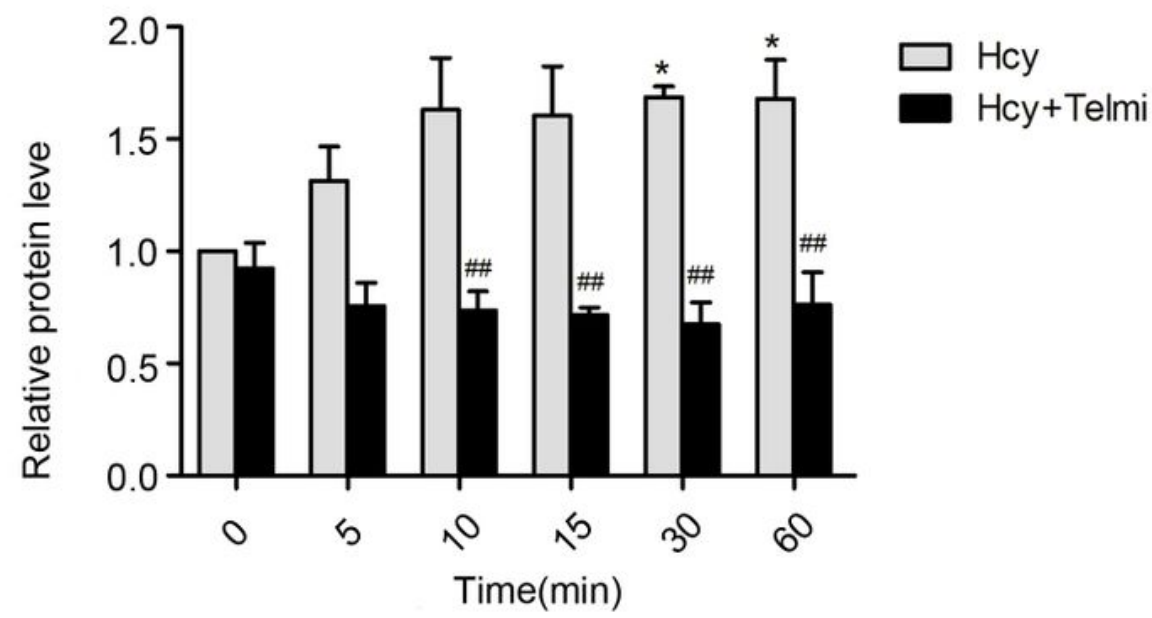

Figure 10

Hcy activates the AT1R downstream G protein-dependent signaling pathways in AFs (a-c) Representative western blots and quantification of phosphorylated and total PKC and ERK1/2 in Hcy (200 $\mu \mathrm{mol} / \mathrm{L})$ treated AFs with or without telmisartan $(1 \mathrm{mmol} / \mathrm{L})$ pretreatment for 60 minutes. $\mathrm{n}=3$. Data represent mean \pm SEM. The data were analyzed by repeated measurement ANOVA. ${ }^{*} \mathrm{P}<0.05, * \star \mathrm{P}<0.01$ intragroup comparison; \#P $<0.05$, \#\# $<0.01$ between groups. 
a

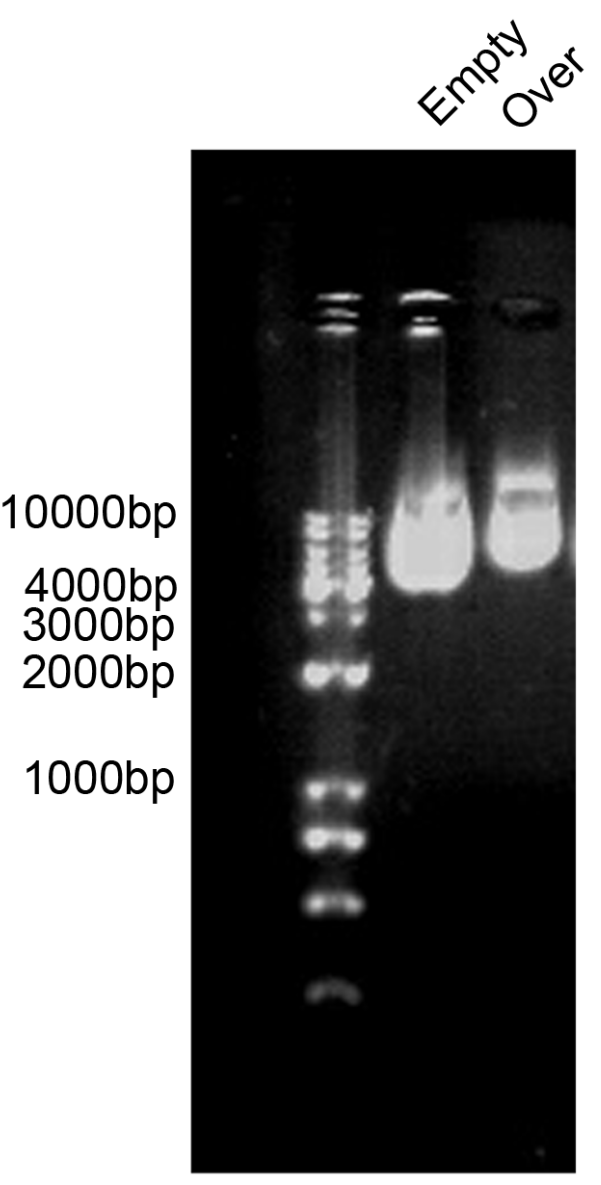

b

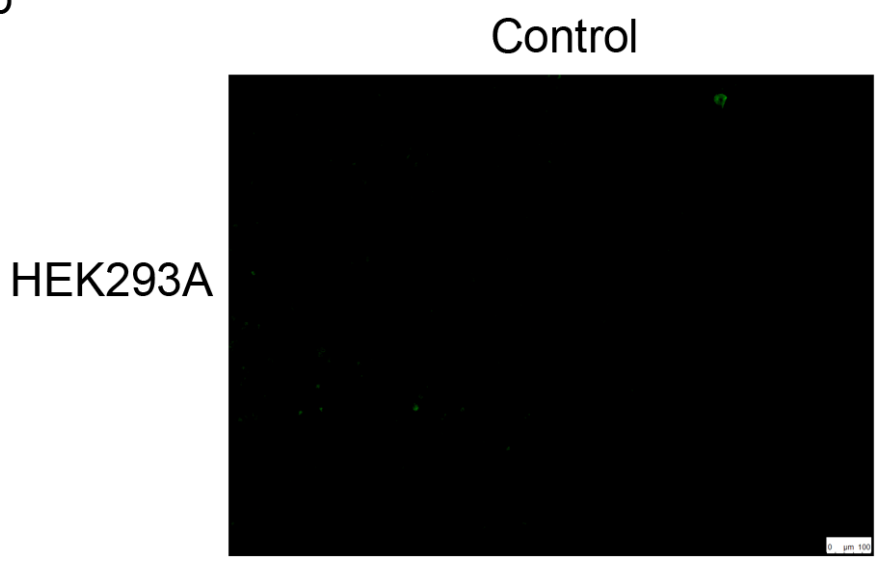

C

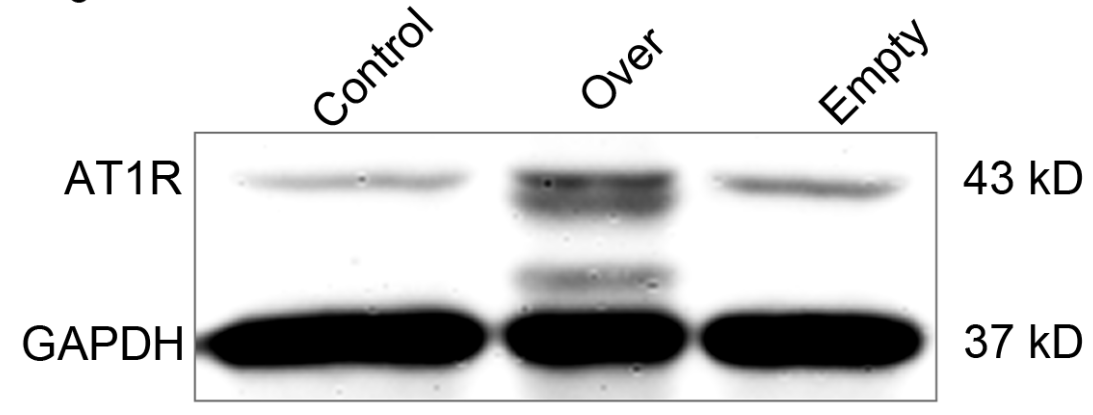

d
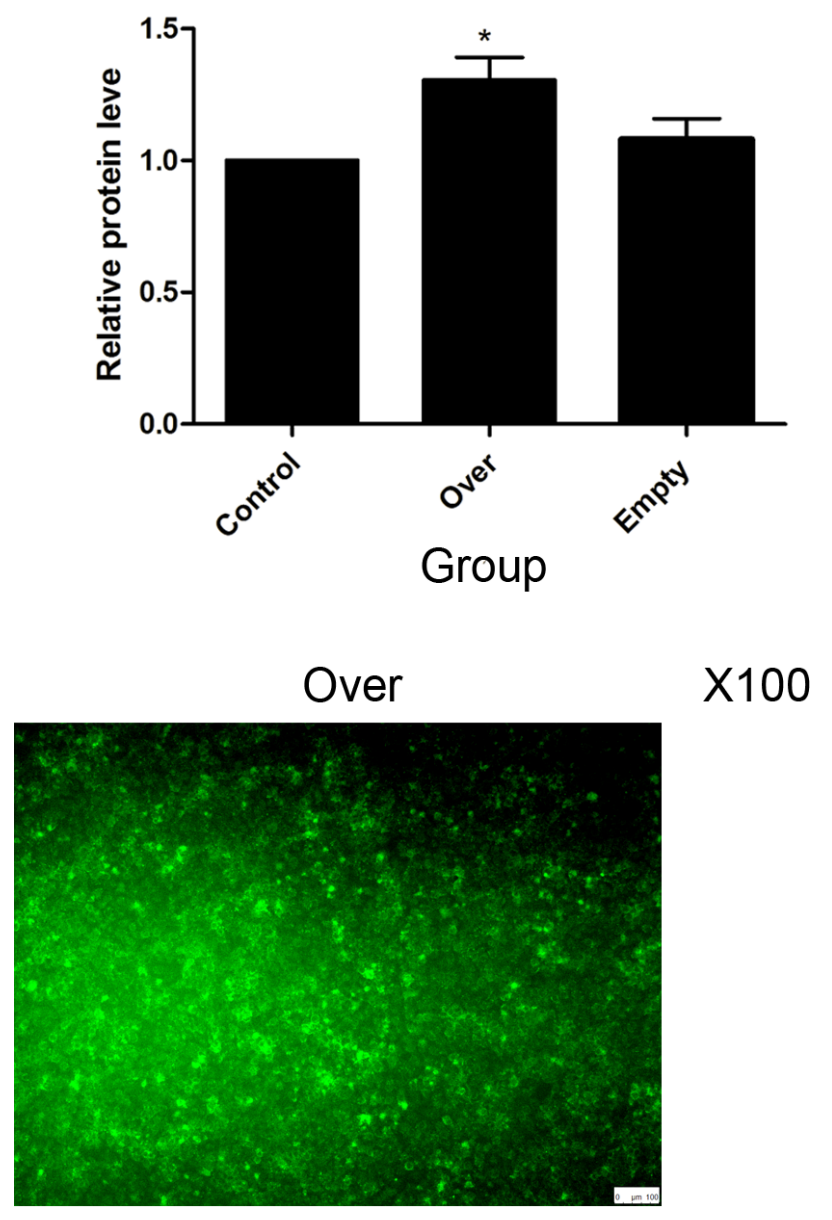

\section{Figure 11}

Expression of target protein in HEK293A cells (a) Agarose gel electrophoresis of plasmid DNA showing representative patterns of empty plasmid and overexpression of plasmid. (b) Expression of green fluorescent protein (EGFP). HEK293A cells transfected with overexpression of plasmid. Scale bar $=100$ $\mu \mathrm{m}$. (c-d) Western blot indicated AT1R levels in HEK293A cells and densitometric analyses. $n=3$. Data represent mean \pm SEM. The data were analyzed by one-way ANOVA. * $P<0.05$ versus control group. Control, HEK293A cells; Over, overexpression of plasmid; Empty, empty plasmid HEK293A cells. 


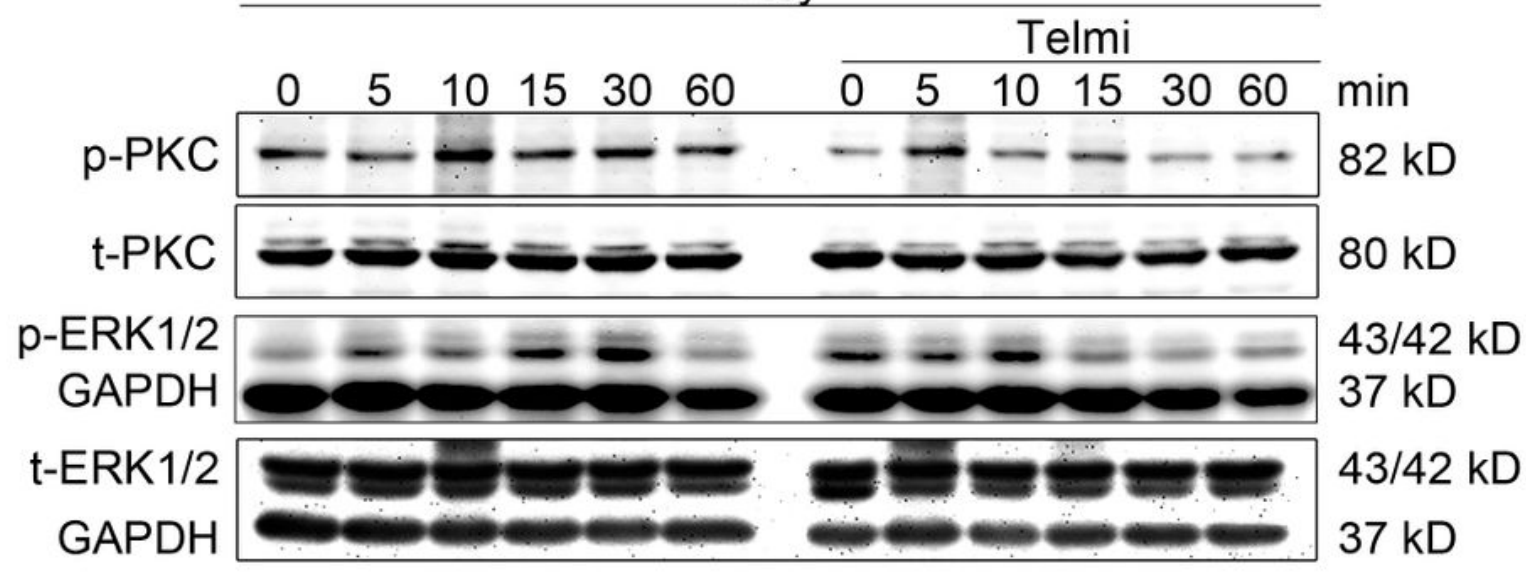

b $\mathrm{p}-\mathrm{PKC} / \mathrm{t}-\mathrm{PKC}$

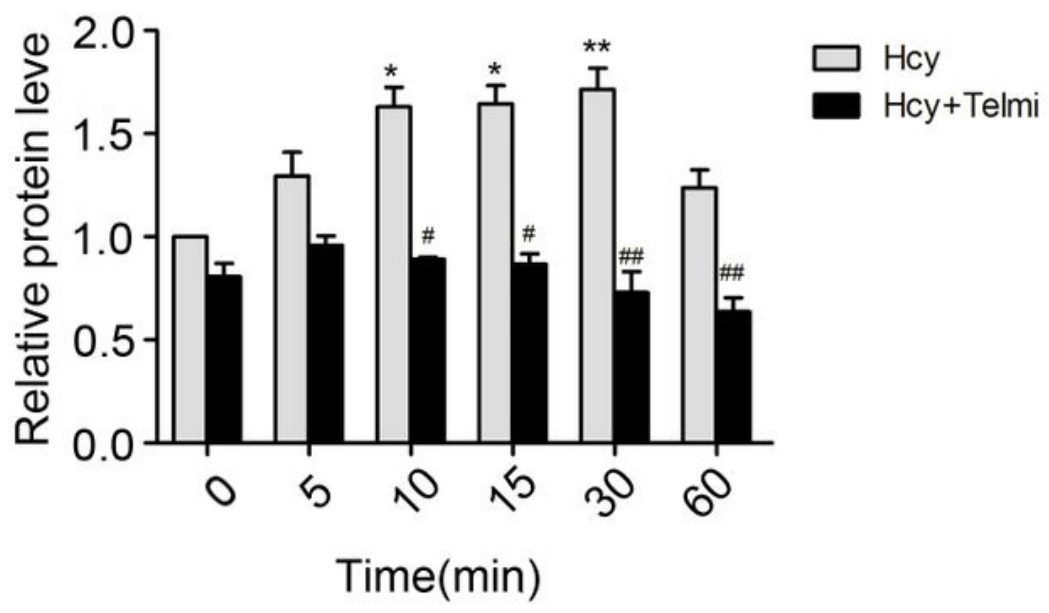

C

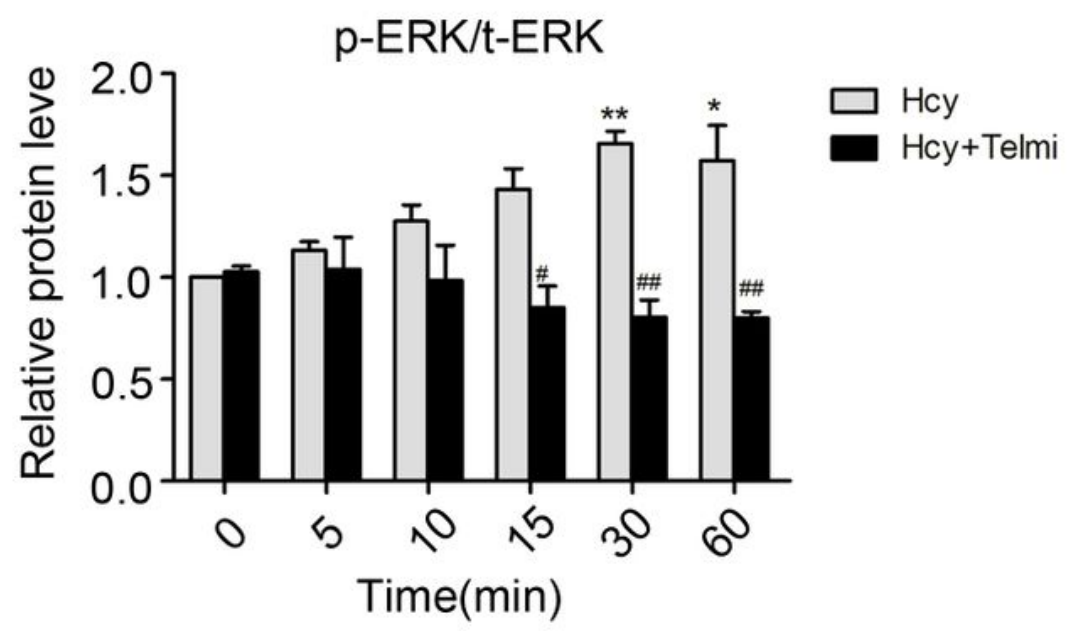

Figure 12

Hcy activates the AT1R downstream G protein-dependent signaling pathways in HEK293A cells. $(a-c)$ Representative western blots and quantification of phosphorylated and total PKC and ERK1/2 in Hcy $(200 \mu \mathrm{mol} / \mathrm{L})$-treated HEK293A cells (transfected with human AT1R) with or without telmisartan (1 $\mathrm{mmol} / \mathrm{L}$ ) pretreatment for 60 minutes. $\mathrm{n}=3$. Data represent mean $\pm S E M$. The data were analyzed by 
repeated measurement ANOVA. ${ }^{*} \mathrm{P}<0.05,{ }^{\star *} \mathrm{P}<0.01$ intragroup comparison; $\# \mathrm{P}<0.05, \# \# \mathrm{P}<0.01$ between groups.

\section{Supplementary Files}

This is a list of supplementary files associated with this preprint. Click to download.

- Fig.13.tif

- Fig.14.tif 